\title{
Gendered diverging destinies: Changing family structures and inequality of opportunity among boys and girls in the United States
}

Diederik Boertien, Centre d'Estudis Demogràfics, dboertien@ced.uab.es

Centre d'Estudis Demogràfics, Carrer de Ca n'Altayó, Edifici E2; Universitat Autònoma de Barcelona, 08193 Bellaterra - ES; Tel: + 34935813060.

Fabrizio Bernardi, European University Institute, fabrizio.bernardi@eui.eu

\section{Abstract}

The prevalence of non-standard family structures has increased over time and in particular among socioeconomically disadvantaged families. Because children's attainments are negatively associated with growing up in non-standard family structures, changes in family structures are often considered to have strengthened the reproduction of social inequalities across generations. We argue that the validity of this argument depends on variation in how family structure affects children's attainments, a premise we label heterogeneity in attainment penalties. Previous research has documented heterogeneity in attainment penalties across social groups and by gender. Therefore, the role of family structure in reproducing inequalities is unclear and might vary by gender too. We use data from the NLSY 1979 and 1997 cohorts to estimate the contribution of changes in family structures to parental education differences in educational attainment for boys and girls. We estimate extended Oaxaca-Blinder decomposition models which take into account both cross-cohort changes in the prevalence of family structures and heterogeneity in related penalties. Changes in the prevalence and penalties related to childhood family structures account for a $15 \%$ increase in the parental education gap in educational attainment for girls but reduced the attainment gap for boys by $13 \%$. 
Keywords: Inequality of Opportunity; Family Structure; Gender; Education; Social Stratification;

Acknowledgement: We would like to thank those present at the opportunities we had to present our work: Berkeley Demography Brown Bag Series, PAA Annual meeting 2018, MZES Sociology Seminar Series Mannheim, Inequality Working Group at the European University Institute.

Funding: Diederik Boertien acknowledges research funding from the Beatriu de Pinos program of the Generalitat de Catalunya (2016-BP-00121), the EQUALIZE project (ERC2014-STG-grant agreement No 637768), and the GLOBFAM project (RTI2018-096730-BI00). 
Families in the United States have profoundly changed over the last decades. The percentage of children living with a single parent increased from roughly $12 \%$ in 1970 to $27 \%$ by 2018 (Smock and Schwartz 2020). Parental separation and childbearing outside of partnership have replaced parental death as the main reason for parental absence in the household (Ellwood and Jencks 2004). Furthermore, many children experience complex family dynamics such as the re-partnering of parents and the entrance of step- or half-siblings into the household (Brown, Stykes, and Manning 2016; Cavanagh and Fomby 2019).

Changes in the prevalence of 'non-standard' family structures across periods have been especially pronounced among poor and lower educated mothers (McLanahan 2004; McLanahan and Jacobsen 2016; Rackin and Gibson-Davis 2018) and living in a household with a non-standard family structure is negatively associated with child outcomes (Amato 2000; 2010). Therefore, various authors have argued that childhood family structures play an increasingly salient role in the reproduction of inequalities across generations (Cherlin 2014; McLanahan and Percheski 2008; Putnam 2016). This argument is part of a broader thesis that changes associated with the second demographic transition have contributed to 'diverging destinies' between children from different socioeconomic backgrounds (McLanahan 2004; McLanahan and Jacobsen 2016).

Despite the prominence of the argument that changes in childhood family structures have strengthened the reproduction of social inequalities across generations, there is only limited research explicitly testing this argument (Alamillo 2016; Bernardi and Boertien 2017; Duncan, Kalil, and Ziol-Guest 2017). Studies on the topic have primarily concentrated on documenting the unequal diffusion of non-standard family structures across socioeconomic groups (Härkönen and Dronkers 2006; Martin 2006; Matysiak, Styrc, and Vignoli 2014; Rackin and Gibson-Davis, 2018), its consequences for cross-sectional levels of income inequality (Esping-Andersen 2007; Martin 2006; Western, Bloome, and Percheski 2008) and 
whether intergenerational mobility is higher within non-standard families (Biblarz and Raferty 1999; Bloome 2014; 2017; Martin 2012). What is lacking from this body of research is a comprehensive effort quantifying the impact of changing family structures on the reproduction of inequalities across generations. In this article we focus on inequality in educational attainment and address the following main research question: have changes in childhood family structures contributed to inequality in educational attainment by parental socioeconomic status (SES) in the United States?

Parallel to changes in family structures, the gender gap in educational attainment reversed from one favoring boys to one favoring girls in the 1980s (Buchmann and DiPrete 2006). Boys and girls generally share the same families, neighborhoods, and schools. Researchers have therefore argued that explanations for the reversal in the gender gap should be based on how boys and girls react differently to the same events and contexts. Several authors have argued that family structure is such a situation and, therefore, might have contributed to the gender gap reversal in educational attainment (Autor et al. 2019; Bertrand and Pan 2013; Chetty et al. 2016; DiPrete et al. 2013; Lundberg 2017). Various studies have shown how non-standard family structures, and father absence in particular, indeed have a greater impact on the educational outcomes of boys (Autor et al. 2019; Bertrand and Pan 2013; Lundberg 2017). If there are systematic gender differences in how childhood family structure matters for attainments, the argument that changing family structures strengthen the reproduction of inequalities across generations might not be equally applicable to boys and girls either. The second main research question of the article is, therefore: are there gender differences in the contribution of family structure changes to inequality in educational attainment by parental socioeconomic status?

Our main contributions are threefold: First, we present an analytical framework to study the contribution of changes in childhood family structures to inequality in educational 
attainment by parental SES. This framework is based on the conceptual distinction between the 'prevalence' of childhood family structures and the 'penalty' for educational outcomes associated with them (Brady, Finnigan, and Hübgen 2017). We add the notion of 'heterogeneity in penalties' to this framework which considers how the penalty for educational attainment associated with growing up in a non-standard family varies depending on the SES of the family (Augustine 2014; Bernardi and Boertien 2017; Brand et al. 2019a; Martin 2012). Second, whereas a handful of previous studies suggested that the cross-sectional contribution of childhood family structure to parental SES differences in educational outcomes is relatively small (Alamillo 2016; Bernardi and Boertien 2017), it is unclear whether the contribution of childhood family structure changed over time as suggested by previous research (McLanahan and Percheski 2008). Therefore, we employ a Blinder-Oaxaca decomposition approach adapted to studying change over time (Kim 2010) and estimate to what extent changes in childhood family structures contributed to changes in parental SES gaps in educational outcomes across cohorts. Third, we add a gender component to the debate on diverging destinies by quantifying the contribution of changes in family structures to parental SES inequality in educational outcomes for boys and girls separately. As it turns out, this refinement is crucial for the conclusions drawn.

We study the educational attainment of respondents from the National Longitudinal Surveys of Youth (NLSY) that started in 1979 and 1997. Whereas the great majority of the first cohort, born in the early 1960s, grew up with both biological parents present in the household, around half of the individuals from the second cohort spent time in what we label 'non-standard' family structures: single-parent families, step-parent families and other family forms where at least one biological parent is not living in the same household as the child. Our specific focus on gender differences and the incorporation of heterogeneity in the effects of family structure into our analytical approach leads us to some unexpected results. 
Even though changes in family structures are indeed related to an important increase in inequality of educational attainment by parental education for girls, they are related to a reduction in the attainment gap for boys.

The explanation for this result is found in how the effects of childhood family structure on educational attainment differ by gender and parental education. In line with recent poverty research (Brady et al. 2017), we conclude that if we want to understand the drivers of inequality of opportunity, more attention should be paid to how people differ in (being able to) dealing with potentially disadvantageous situations ('heterogeneity in the penalty'), rather than solely focusing on the distribution of such situations across the population ('prevalence').

\section{FAMILY STRUCTURE AND INEQUALITY OF OPPORTUNITY: AN ANALYTICAL FRAMEWORK}

Figure 1 graphically represents our analytical framework to empirically test whether childhood family structure indeed plays an increasingly important role in the reproduction of social inequalities across generations. Arrow $\alpha$ indicates inequality in children's outcomes (for instance educational attainment) by parental socioeconomic status (SES). Two conditions have to be met for family structures to explain a part of inequality by parental SES in children's outcomes (Baron and Kenny 1986); a simple question of mediation.

Firstly, parental SES should be related to childhood family structure (Arrow $\beta$ ). Secondly, childhood family structure should affect outcomes (Arrow $ү$ ). Following earlier research on poverty (Brady et al. 2017), we label the first condition (arrow $\beta$ ) as one of the socioeconomic differences in the 'prevalence' of family structures, and the second condition (arrow $\gamma$ ) as the 'penalty' related to growing up in a non-standard family structure. There 
exists ample empirical evidence that both conditions hold (Amato 2010; McLanahan and Percheski 2008; McLanahan and Jacobsen 2016). Therefore, the argument that family structure is a mediator in the reproduction of inequalities across generations seems prima facie supported. As childhood family structure has become increasingly stratified by social origin (i.e. the association expressed by arrow $\beta$ has become stronger), it should follow that changes in family structures over time have increased parental SES differences in outcomes.

Figure 1. Graphical Representation of the Components Constituting the Contribution of Childhood Family Structure to Parental SES Differences in Outcomes

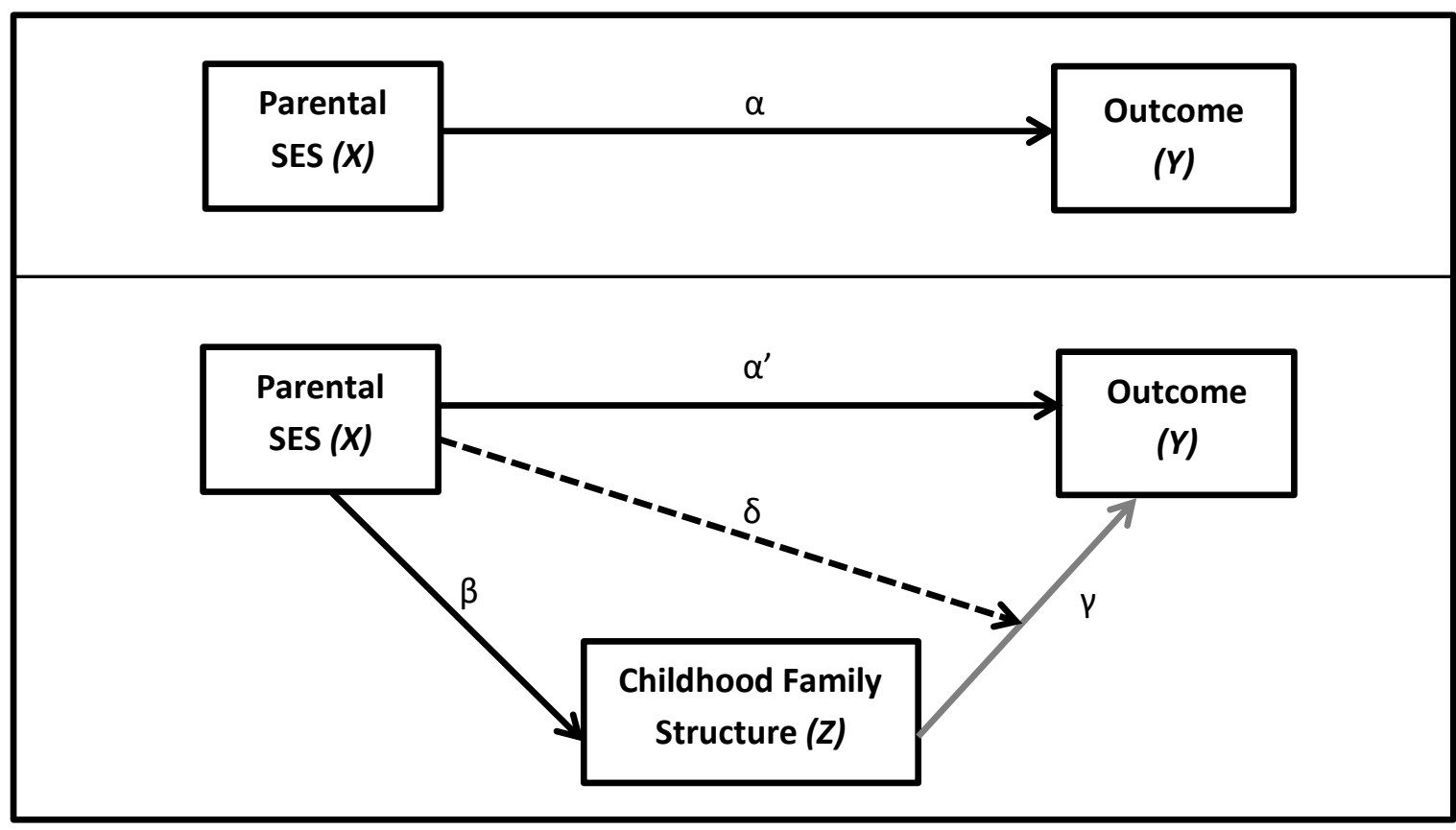

Despite its intuitive appeal, there are at least two qualifications that have to be made to this argument. The first qualification regards effect sizes. The part of the effect of parental SES $(\mathrm{X})$ on education $(\mathrm{Y})$ that is mediated by family structure $(\mathrm{Z})$ depends both on the effect of $\mathrm{X}$ on $\mathrm{Z}$ and the effect of $\mathrm{Z}$ on $\mathrm{Y}$. If one of these two effect sizes is relatively weak, the mediating effect of family structure will be relatively small too. Because previous research has shown that the effects of childhood family structure on education are relatively modest in size (Amato 2010; Bernardi and Boertien 2017), one might expect that the extent to which 
childhood family structure can mediate inequality of educational attainment by parental SES is relatively modest too.

A second reason the influence of family structure on inequality of opportunity could be relatively modest stems from the observation that not everyone is affected equally by growing up in a non-standard family. A growing body of research has addressed the question to what extent the effects of family structure and transitions between them differ according to parental SES (Augustine 2014; Martin 2012). We label this argument as one about 'heterogeneity in penalties' related to growing up in a non-standard family. This is illustrated by Arrow $\delta$ in Graph 2: the effect of family structure on education can be moderated by parental SES. Heterogeneity in penalties by parental SES can either reduce or amplify the contribution of changing family structures to inequality of opportunity (Bloome 2017). Put in extremes, if growing up in a non-standard family negatively affects the outcomes of individuals with high parental SES but not the outcomes of individuals with low parental SES, the increasing prevalence of non-standard family structures might reduce inequality of opportunity, even if non-standard families are concentrated among disadvantaged individuals. Conversely, if childhood family structures only impact the outcomes of individuals with low parental SES, the mediating role of family structures might be greater than expected.

\section{EXISTING EVIDENCE: FAMILY STRUCTURE AND THE POLARIZATION OF OPPORTUNITIES}

In the next sections, we review existing evidence for each of the components that jointly determine the contribution of childhood family structure to parental SES differences in educational attainment: parental SES differences in the 'prevalence' of childhood family 
structures, the general 'penalty' related to childhood family structures, and heterogeneity in these penalties by parental SES.

\section{Socioeconomic status differences in the prevalence of childhood family structures}

The share of children that grows up in a two-parent family has declined over the last decades. The prevalence of 'non-standard' family forms, such as one- and step-parent families, has increased pronouncedly, and especially so within the lower socioeconomic strata (Ellwood and Jencks 2004; Martin 2006; McLanahan and Percheski 2008). In a recent update of the original 'diverging destinies' article, McLanahan and Jacobsen (2016) documented that $11 \%$ of lower educated mothers were single in the $1960 \mathrm{~s}$, but that this share had risen to almost $50 \%$ by 2010 . The corresponding numbers for higher educated mothers were $4 \%$ and $10 \%$ respectively. Single motherhood can be the result of giving birth outside of a partnership, or due to family structure transitions after birth. There is a clear socioeconomic gradient in giving birth outside of partnerships and transitions between family structures are more common among lower-educated mothers (Rackin and GibsonDavis 2018). Similarly, more complex family dynamics such as multi-partner fertility are more common among lower-educated mothers too (Thomson et al. 2014).

\section{The attainment 'penalties' related to childhood family structures}

Studies on the associations between childhood family structures and later outcomes generally conclude that individuals who grew up in a non-standard family structure do slightly to moderately worse on average than individuals who grew up in a two-parent family (Amato 2000; Amato 2010; Härkönen, Bernardi and Boertien 2017). Associations with some outcomes appear to be relatively small, such as cognitive ability, whereas the impact of family structure on others, such as educational attainment and psychological well- 
being, is more substantial (Bernardi and Boertien 2016; Lee and McLanahan 2015; McLanahan, Tach, and Schneider 2013).

Discussion exists regarding the extent to which these associations reflect causal effects or capture the effects of other pre-existing socioeconomic disadvantages. Once accounting for sources of endogeneity, most studies find that the effects of family structure persist but are attenuated. Again, evidence for a causal effect of family structure is clearer for educational attainment than for cognitive ability (Härkönen et al. 2017; McLanahan et al. 2013).

Besides selection, various perspectives are on offer regarding the characteristics of nonstandard family structures that affect children's outcomes. Most children living in a nonstandard family experienced a parental separation which requires emotional adjustment to a parental break-up and could lead to conflict between parents (Cherlin 1999; Kalmijn, Loeve, Manting 2007; Pryor and Rodgers 2001; Thomson, Hanson, and McLanahan 1994). Many scholars have emphasized differences in parenting styles and lower levels of financial resources among non-standard family forms as additional explanations why family structure is related to children's outcomes (Amato 2010; McLanahan and Sandefur 1994; Seltzer 2000). Other authors suggest that it is the stability of family structures that matters for child development rather than particular characteristics of given family forms (Fomby and Cherlin 2007; Waldfogel, Craigie, and Brooks-Gunn 2010). From that perspective, it is the number of transitions between family structures that children experience that is responsible for variation in children's outcomes. The kind of transition made, such as the transition into a single-parent or step-family is relatively less important. Empirical support for this view, however, is still mixed. The number of family structure transitions children experience does matter for certain outcomes including their cognitive ability (Fomby and Osborne 2016; Lee and McLanahan 2015). At the same time, children in stable single-parent families do worse than children in other stable family structures (Magnuson and Berger 2009; Mariani, Özcan, 
Goisis 2017), and parental separation appears to be more impacting than other family transitions such as the moving in of a new partner (Bzostek and Berger 2017; Lee and McLanahan 2015).

\section{Heterogeneity in penalties by parental SES}

An increasing body of research has investigated how the association of childhood family structure with attainments varies across socioeconomic groups. Children from resourceful families might have more to lose from the absence of a parent in the household than children from families with fewer resources (Kalmijn 2010). If economic resources and other forms of parents' capital are best accessed through co-residence, children of high-SES parents will lose access to relatively more resources than children with low-SES parents. For instance, it might be more difficult to finance a college education if parents have to maintain two separate households (Bernardi and Boertien 2016) or to maintain intensive parenting strategies (Lareau 2002) within single-parent families. To put it differently, the transmission of social, economic and human capital can be stronger among two-parent families as compared to family forms where one parent is absent from the childhood home (Coleman 1988).

Several studies have indeed shown that the intergenerational transmission of occupation, education, and income is weaker in non-standard family forms as compared to two-parent families (Biblarz and Raferty 1999; Bloome 2017; Martin 2012). At the same time, empirical studies that have explicitly looked at parental SES differences in the effects of childhood family structures come to varying conclusions. With some exceptions (Augustine 2014), most studies looking at educational attainment find that children from higher SES backgrounds are affected more by growing up in a non-standard family compared to children from lower SES backgrounds (Martin 2012; McLanahan and Sandefur 1994). This 
would suggest that childhood family structure might be less important for the reproduction of inequality across generations than previously thought (Bernardi and Boertien 2017).

\section{Family structure and the gender gap in educational attainment}

Heterogeneity in the effects of childhood family structure has also become a central concern for studies on the reversal of the gender gap in educational attainment (DiPrete and Buchmann 2013). As boys and girls share, on average, the same environment, explanations for the reversal in the gender gap have focused on how boys and girls react differently to given events and situations. There is relatively consistent evidence that the educational outcomes of boys depend more on the academic environment at school and the socioeconomic characteristics of their families than the educational outcomes of girls (Autor et al. 2019; Brenøe and Lundberg 2018; Buchmann and DiPrete 2006; Chetty et al. 2016; Legewie and DiPrete 2012). Why boys' outcomes depend more on their environment is not entirely clear, but a prominent explanation has focused on the construction of gender identities (DiPrete and Buchmann 2013; Legewie and DiPrete 2012). Some conceptions of masculinity include anti-school attitudes and behaviors, whereas other conceptions include academic competition as a way of 'doing' masculinity (Legewie and DiPrete 2012). Conceptions of femininity appear to vary less in the extent to which academic performance is valued. Therefore, boys arguably benefit more from environments that promote academic performance and competition as compared to girls (DiPrete and Buchmann 2013).

Within this body of literature, family structure has been viewed as a factor that shapes the academic environment and, therefore, is a possibly important driver of the gender gap in educational outcomes (Autor et al. 2019; Bertrand and Pan 2013; Buchmann and DiPrete 2006; Chetty et al. 2016). Reviews of gender differences in the effects of family structure on child and adult outcomes, in general, do not give a picture of consistent results (Amato 2001). But, recent studies focusing on educational achievement, non-cognitive skills, and 
high school completion report larger effects of family structure on the performance and attainment of boys than on the outcomes of girls (Autor et al. 2019; Bertrand and Pan 2013; Buchmann and DiPrete 2006; Chetty et al. 2016). Evidence for gender differences in effects on final educational attainment is less uniform (Duncan et al. 2017 and Lundberg 2017). But overall, there are reasons to expect that boys and girls react differently to growing up in a given family structure. Therefore, the contribution of childhood family structure to parental SES differences in educational outcomes might differ by gender too.

\section{The quantification of the role of family structure in amplifying inequalities}

Up to date, the existing evidence quantifying the contribution of changes in childhood family structures to socioeconomic inequality of opportunity is limited to three studies. However, these studies either did not take into account heterogeneity in the penalties related to family structure (Duncan et al. 2017) or did not look at changes over time and differences by gender (Alamillo 2016; Bernardi and Boertien 2017). All three studies concluded that the contribution of family structure to inequality in educational attainment by parental SES is rather small. We add to these previous studies by simultaneously focusing on change over time and taking into account heterogeneity in penalties by parental SES and gender. This broader framework allows us to uncover more nuanced findings and conditions under which changes in the prevalence of childhood family structures matters for the reproduction of inequalities across generations. Indeed, these refinements appear to have important consequences for the conclusions drawn.

\section{DATA AND METHOD}

We employ data from the National Longitudinal Surveys of Youth (NLSY) 1979 (NLYS79) and 1997 (NLSY97). ${ }^{1}$ The NLSY cohorts are nationally representative samples of 
adolescents who were aged 14 to 22 in 1979 and aged 12 to 18 in 1997, respectively. Of all eligible respondents selected in the first round, $87 \%$ ended up being interviewed in 1979; for the 1997 cohort, this percentage was 91\%. By the 1994 wave of the 1979 cohort (the last wave used here), $89 \%$ of the sample interviewed in round 1 was still present. For the 1997 cohort, almost $80 \%$ was still present in the most recently available wave (2015). Black and Hispanic adolescents were oversampled in the study, and sample weights are used in the analysis to take this overrepresentation into account. Some respondents lived in the same household during childhood and standard errors are therefore clustered by the original household in the analysis.

We exclude respondents who lived with adoptive parents from our sample (as the mechanisms determining educational opportunities might be very different for them). For our main analysis, cases with missing information on the variables of the analysis are discarded (excluding $16.5 \%$ of the sample for the NLYS79 and $10.9 \%$ of cases for the NLSY97). In robustness checks, we use multiple imputations to deal with missing values (See "Robustness Checks" section). The final sample sizes used are 7,422 for the NLSY79 and 6,379 for the NLSY97. We replicate our findings using data from the General Social Survey; more details are provided in the "Robustness Checks" section.

\section{Variables}

The attainment of a Bachelor's Degree by the time of the survey is our main educational attainment variable and is measured when respondents reached their early 30s for both cohorts (in 1994 for the 1979 cohort and 2015 for the 1997 cohort). In robustness checks, we also look at High School Completion which indicates having a high school degree or GED, and Years of Education completed at the time of the survey. 
We use Mother's Highest Level of Education as our preferred indicator of parental SES. Even though mothers' educational careers can be altered due to family structure changes at young ages, alternative measures, such as income and occupation at the time of the survey, are likely to be affected more directly by family structure. Mother's education is chosen over father's education as the latter is more often missing ( $9 \%$ for fathers, compared to $2 \%$ for mothers), and especially so for those in non-standard families (e.g. those who never lived with their father). ${ }^{2}$ For each cohort, we create three broad maternal education categories of similar size (bottom, mid, top). We defined the bottom of the maternal education distribution as those who had completed grade 8 or less for the 1979 cohort $(16.5 \%)$ and grade 11 or less for the 1997 cohort $(18.3 \%)$. The top of the distribution consisted of mothers who had completed at least one year of college in $1979(21.3 \%)$ and at least four years of college in $1997(20.7 \%)$. Hence, the bottom and top categories resemble the lowest and highest quintile of maternal education within each cohort. ${ }^{3}$

The main independent variable of the analysis is childhood family structure. For both datasets family structure was measured at age 17. Four main categories of family structures were considered: living with both biological parents, living with a parent and a step-parent, living with a single parent, and not living with any biological parent at all. This rather crude classification of family structures is the main limitation of our analysis. Unfortunately, the NLSY97 only provides patchy retrospective information on childhood family structure, ${ }^{4}$ preventing us from being able to construct comparable measures capturing more complex childhood family structure trajectories for both datasets. Repeated family transitions are more common among socioeconomically disadvantaged groups (Brown et al. 2016). Eventual larger penalties related to childhood family structures among individuals with lower educated mothers might therefore to some extent reflect the effects of a higher number of family transitions experienced by them. For the 1979 cohort, we perform additional 
analysis using the NLSY79 data using more detailed childhood family structure histories. These additional models show that 'penalties' for educational attainment are very similar across non-standard family structure trajectories. In addition, cross-sectional decomposition methods using more refined measures of childhood family structure trajectories yielded very similar results to the ones presented in this article. ${ }^{5}$ We discuss this issue further in the discussion.

Control variables included in the analysis are region (Northeast, North Central, South, West), age, gender, and ethnicity (Black, Hispanic, and Non-Black / Non-Hispanic). Descriptive statistics of both samples and variables are displayed in Table 1.

\section{Decomposition procedure}

We use an extended Blinder-Oaxaca decomposition approach (Kim 2010; Smith and Welch 1989) to estimate how much family structure changes across cohorts contributed to inequality in educational outcomes by parental SES. The decomposition analysis is performed separately for boys and girls. As will become clearer, the terms of the decomposition closely correspond to the notions of prevalence, penalty, and heterogeneity in penalties introduced in our analytical framework.

The objective of the decomposition is to explain changes in $D$ which represents the absolute difference in the outcome variable $Y$ of individuals in Group $h$ and Group $l$ (e.g. children with highly and less educated mothers):

$D=Y_{h}-Y_{l}$

And $\Delta D$ represents the absolute change over time in this group difference between periods 0 and 1: 
Table 1. Descriptive Statistics of the Samples Used

\begin{tabular}{|c|c|c|c|c|}
\hline & \multicolumn{2}{|l|}{ NLSY 79} & \multicolumn{2}{|l|}{ NLSY 97} \\
\hline & Average / \% & $\begin{array}{l}\text { Standard } \\
\text { Deviation }\end{array}$ & Average / \% & $\begin{array}{l}\text { Standard } \\
\text { Deviation }\end{array}$ \\
\hline \multicolumn{5}{|l|}{ Outcome Variables } \\
\hline Bachelor Degree completion & 24.1 & & 33.3 & \\
\hline Years of education & 13.4 & 2.5 & 14.1 & 3.0 \\
\hline High school/GED completion & 90.3 & & 93.3 & \\
\hline
\end{tabular}

\section{Family Structure at age 17}

Living with both biological parents

72.2

Living with a parent and step-parent

Living with a single parent

28.1

Not living with any parent

\section{Maternal Education}

Bottom 'quintile'

Middle

Top 'quintile'

\section{Control Variables}

Respondent's age at interview

Black

Hispanic

Mixed Race (Non-Hispanic) 
Then $\Delta \mathrm{D}$ can be decomposed as follows, where $\bar{X}_{S}$ is the share of a given group and cohort having lived in childhood family structure type $s$ and $\beta_{S}$ expresses the related OLS coefficients for each childhood family structure type, cohort, and group: ${ }^{6}$

$$
\Delta D=\underbrace{\left(A_{h 1}-A_{h 0}\right)-\left(A_{l 1}-A_{l 0}\right)}_{\text {Intercept effect }}
$$

$$
+\underbrace{\sum_{s}\left\{\left[\left(\beta_{s h 1}+\beta_{s h 0}\right) / 2\right]-\left[\left(\beta_{s l 1}+\beta_{s l 0}\right) / 2\right]\right\}\left\{\left[\left(\bar{X}_{s h 1^{-}} \bar{X}_{s h 0}\right)+\left(\bar{X}_{s l 1^{-}} \bar{X}_{s l 0}\right)\right] / 2\right\}}_{\text {Effect of general changes in prevalence }}
$$

$+\underbrace{\sum_{s}\left[\left(\bar{X}_{s h 1^{-}} \bar{X}_{s h 0}\right)-\left(\bar{X}_{s l 1^{-}} \bar{X}_{s l O}\right)\right]\left[\left(\beta_{s h 1}+\beta_{s h 0^{+}} \beta_{s l 1}+\beta_{s l 0}\right) / 4\right]}$

Effect of parental SES differences in changing prevalence

$$
+\underbrace{\sum_{s}\left\{\left[\left(\bar{X}_{s h 1}+\bar{X}_{s h 0^{\prime}}\right) / 2\right]-\left[\left(\bar{X}_{s l 1}+\bar{X}_{s l 0}\right) / 2\right]\right\}\left[\left(\beta_{s h 1^{-}} \beta_{s h 0}\right)+\left(\beta_{s l 1^{-}} \beta_{s l 0}\right) / 2\right]}_{\text {Effect of general changes in penalties }}
$$

$$
+\underbrace{\sum_{s}\left[\left(\beta_{s h 1}-\beta_{s h 0}\right)-\left(\beta_{s l 1}-\beta_{s l 0}\right)\right]\left[\left(\bar{X}_{s l 1}+\bar{X}_{s l 0^{+}}+\bar{X}_{s h 1}+\bar{X}_{s h 0}\right) / 4\right]}
$$

Effect of changing heterogeneity in penalties by parental SES

Part 3.i of this equation expresses the changes over time in group differences that cannot be accounted for by changes in the prevalence of family structures and related penalties and is labeled the "intercept effect". The parts 3.ii to 3.v together quantify the overall change in the contribution of childhood family structures to the cross-cohort change in group differences $\Delta D$.

Part 3.ii captures the effect of overall changes in the prevalence of the various non-standard family structures. If the penalty related to growing up in a given family structure is stronger for one group (on average across cohorts), increases in the prevalence of this family structure type will have a greater impact on the outcomes of this group. In other words, if 
both groups experience a change from $90 \%$ two-parent families to $50 \%$ two-parent families, this will be more consequential for the group where the penalties of not growing up in such a family structure are higher. Therefore, this component takes the average change in family structure composition across both groups $\left\{\left[\left(\bar{X}_{s h 1^{-}} \bar{X}_{s h 0}\right)-\left(\bar{X}_{s l 1^{-}} \bar{X}_{s l O}\right)\right] / 2\right\}$ and multiplies it by the parental SES heterogeneity in penalties related to family structures $\left[\left(\beta_{s h 1}+\beta_{s h 0}\right) / 2\right]-$ $\left[\left(\beta_{s l 1}+\beta_{s l 0}\right) / 2\right]$

Part 3.iii measures the impact of differential changes in the prevalence of family structure types according to parental SES. In other words, $\left[\left(\bar{X}_{s h 1^{-}} \bar{X}_{s h 0}\right)-\left(\bar{X}_{s l 1^{-}} \bar{X}_{s l 0}\right)\right]$ captures changes in the prevalence of family structure types across maternal education groups. This component is weighted by the 'average' penalty of growing up in a given family structure, which is an average of the coefficients $\beta$ observed across all groups and cohorts $[(\beta \operatorname{sh} 1+$ $\beta$ sh0 $+\beta$ sl1 $+\beta$ s10)/4]. This component represents the 'diverging destinies' prediction in its simplest form: SES differences in how the prevalence of family structures changed over time amplified group differences in outcomes.

However, the penalties related to non-standard childhood family structures change over time. Average changes over time in penalties affect group differences because they will be more consequential for SES groups with higher shares of individuals living in households with non-standard family structures. Part 3.iv quantifies the influence of average changes over time in penalties. This component weighs the average change in penalties across cohorts $\left[\left(\beta_{s h 1}+\beta_{s h 0}\right) / 2\right]-\left[\left(\beta_{s l 1}+\beta_{s l 0}\right) / 2\right]$ by parental SES differences in the prevalence of family structures $\left\{\left[\left(\bar{X}_{s h 1^{-}} \bar{X}_{s h 0}\right)-\left(\bar{X}_{s l 1^{-}} \bar{X}_{s l 0}\right)\right] / 2\right\}$.

Finally, component 3.v takes into account that not only the average penalties related to family structure types change over time but also the heterogeneity in penalties by parental 
SES. It weighs the change in socioeconomic differences in penalties $\left(\beta_{s h l}-\beta_{s h 0}\right)-\left(\beta_{s l 1^{-}}\right.$ $\left.\beta_{s l 0}\right)$ by the average prevalence of the family structure type across groups and cohorts $\left[\left(\bar{X}_{s l 1}+\bar{X}_{s l 0^{+}}+\bar{X}_{s h 1}+\bar{X}_{s h 0}\right) / 4\right]$

In what follows, we report and discuss the results for each of the components of the decomposition in turn. We first present findings based on OLS regression models, and subsequently quantify the contribution of each component to socioeconomic gaps in educational outcomes. Empirically accounting for endogeneity in studies on family structure has been a challenge (McLanahan et al. 2013), and we are not able to tackle this issue to a satisfactory extent in this paper either. At the same time, previous research on endogeneity and causality gives us good indications on how to interpret our results. Therefore, after presenting our decomposition results we reflect on the extent to which accounting for endogeneity might modify our conclusions.

\section{RESULTS}

Figure 2 documents how educational attainment has changed across cohorts depending on maternal education and gender. Bachelor's degree attainment increased across all groups but especially so among girls with higher educated mothers. The attainment gap between boys with lower and higher educated mothers increased from a 47.6 percentage point difference for the 1979 cohort to a 50.1 difference for the 1997 cohort. For girls, the increase in the gap was greater and augmented from 46.1 to 58.6 percentage points across cohorts. The remainder of the analysis will quantify to what extent changes in the prevalence of family structures and related penalties contributed to these increases in educational attainment differences across cohorts. We first document how the prevalence and penalties of childhood 
family structures changed across cohorts, and subsequently present our decomposition results.

Figure 3 shows changes in the prevalence of four broad categories of family structure types across both cohorts. The prevalence of two-parent families declined, and non-standard family structures became more common for all groups considered. Increases were more pronounced among individuals with lower educated mothers, and the gap between children of lower and higher educated mothers in the prevalence of two-parent families increased from 13 to 29 percentage points across cohorts.

Figure 2. Bachelor's Degree attainment by cohort, gender, and maternal education

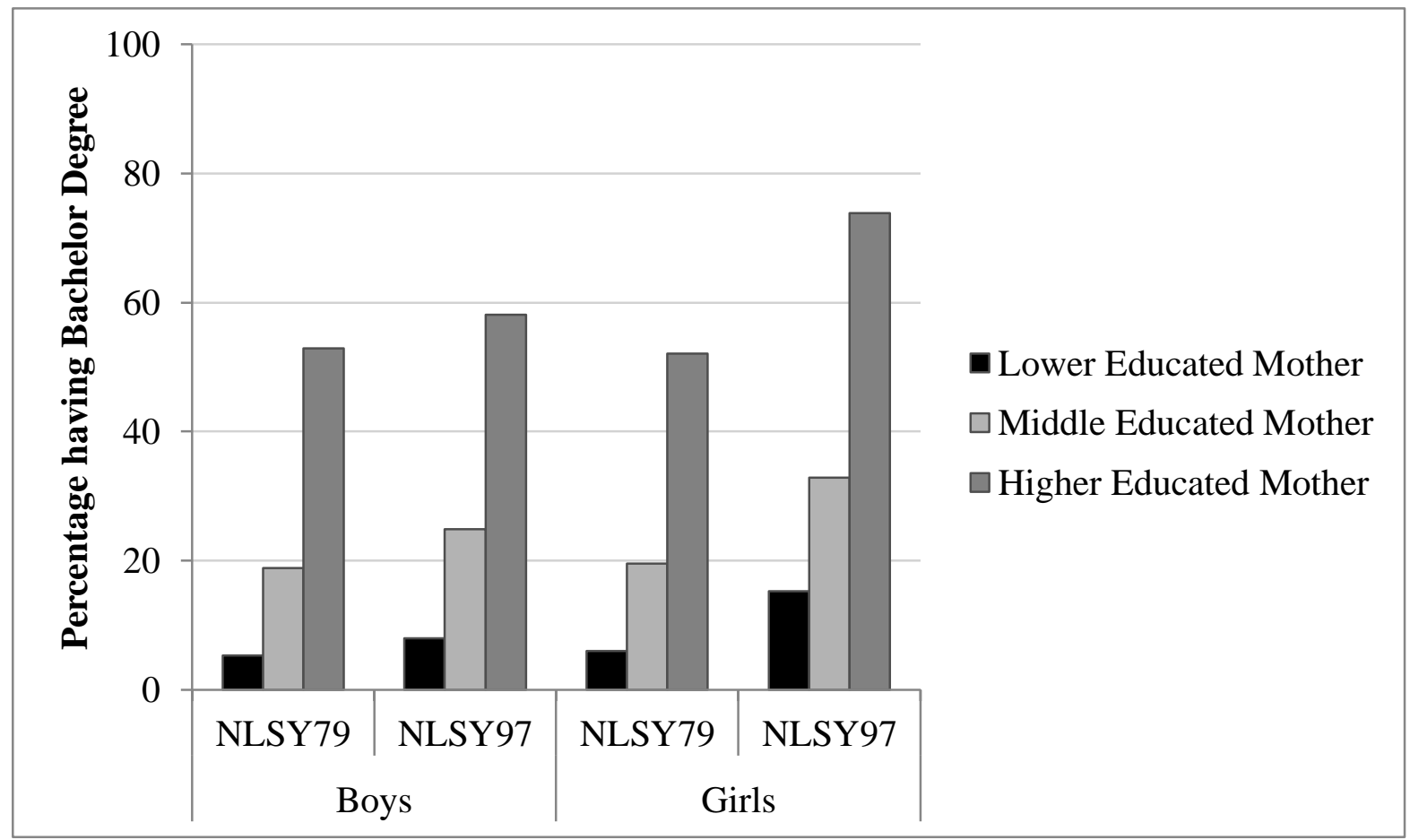

Note. Lower Educated Mothers: Did not complete grade 12; Middle Educated Mothers: Grade 12 completed, but less than 4 years of college; Higher Educated Mothers: 4 years of college or more. 
Figure 3. Family structure at age 17 by cohort and mother's education

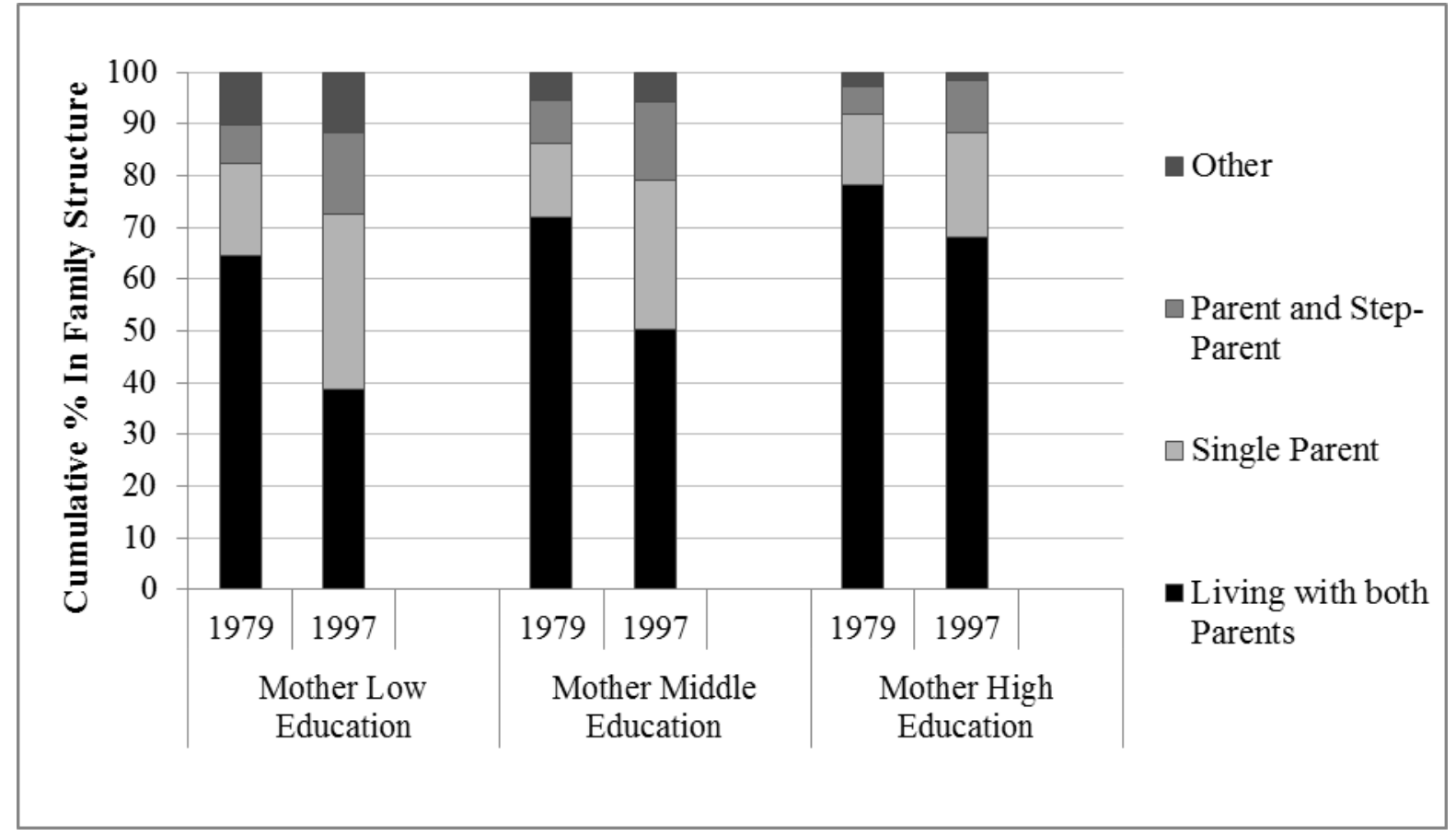

Note. Note. Lower Educated Mothers: Did not complete grade 12; Middle Educated Mothers: Grade 12 completed, but less than 4 years of college; Higher Educated Mothers: 4 years of college or more.

Models 1 and 4 in Table 2 show the association of various childhood family structures with Bachelor's degree attainment. Both boys and girls who lived in a non-standard family structure at age 17 attained fewer degrees than their counterparts who lived in two-parent families, and this conclusion holds for all the different non-standard family structures considered. Effect sizes range from 10 percentage points for boys who lived with a single parent to 21 percentage points for girls who did not live with either biological parent at age 17. In line with previous results of Lundberg (2017), we do not observe clear gender differences in the effect of childhood family structures on final educational attainment, and if so, effect sizes appear larger for girls. All non-standard family forms are grouped in a single category for the remaining models to be more succinct, but the detailed categories will be used again in the decomposition analysis. Models 3 and 6 of Table 2 show that the penalty of having lived in a non-standard family more or less doubled across cohorts for boys and girls alike. 
Table 2. LPM models explaining Bachelor Degree attainment

\begin{tabular}{|c|c|c|c|c|c|c|c|c|c|c|c|c|}
\hline & \multicolumn{6}{|c|}{ Men } & \multicolumn{6}{|c|}{ Women } \\
\hline & \multicolumn{2}{|l|}{ Model 1} & \multicolumn{2}{|l|}{ Model 2} & \multicolumn{2}{|l|}{ Model 3} & \multicolumn{2}{|l|}{ Model 4} & \multicolumn{2}{|l|}{ Model 5} & \multicolumn{2}{|l|}{ Model 6} \\
\hline & Coef. & $\mathrm{SE}$ & Coef. & SE & Coef. & SE & Coef. & $\mathrm{SE}$ & Coef. & $\mathrm{SE}$ & Coef. & $\mathrm{SE}$ \\
\hline $\begin{array}{l}\text { Family structure at age } 17 \\
\text { (Ref. two-parent family) }\end{array}$ & & & & & & & & & & & & \\
\hline Parent and Step-Parent & $-0.11 * * *$ & 0.02 & . & & . & & $-0.19 * * *$ & 0.02 & . & & . & \\
\hline Single Parent & $-0.10 * * *$ & 0.01 & . & & . & & $-0.12 * * *$ & 0.02 & . & & . & \\
\hline No biological parent & $-0.16^{* * *}$ & 0.02 & . & & . & & $-0.21 * * *$ & 0.02 & . & & . & \\
\hline $\begin{array}{l}\text { Non-standard family } \\
\text { (Ref. two-parent family) }\end{array}$ & . & & $-0.11 * * *$ & 0.01 & $-0.07 * * *$ & 0.02 & . & & $-0.16^{* * *}$ & 0.01 & $-0.11 * * *$ & 0.02 \\
\hline $\begin{array}{l}\text { NLSY97 cohort } \\
\text { (Ref. } 79 \text { cohort) }\end{array}$ & $0.08 * * *$ & 0.01 & $0.08 * * *$ & 0.01 & $0.11 * * *$ & 0.02 & $0.18 * * *$ & 0.01 & $0.18 * * *$ & 0.01 & $0.22 * * *$ & 0.02 \\
\hline Non-standard family X cohort & . & & . & & $-0.09 * * *$ & 0.02 & . & & . & & $-0.10 * * *$ & 0.02 \\
\hline Constant & $0.06 * * *$ & 0.02 & $0.06 * * *$ & 0.02 & $0.05 * * *$ & 0.02 & $0.10 * * *$ & 0.02 & $0.09 * * *$ & 0.02 & $0.08 * * *$ & 0.02 \\
\hline $\mathrm{N}$ & 6,783 & & & & & & 7,018 & & & & & \\
\hline
\end{tabular}

Controls included: age, maternal education, region and ethnicity. Sample weights included. $* * * p<0.001 * * p<0.01 ; * p<0.05 ; \dagger p<0.10$.

Standard errors clustered by original household. 
Table 3. LPM models explaining Bachelor Degree attainment

\begin{tabular}{|c|c|c|c|c|c|c|c|c|}
\hline & \multicolumn{4}{|c|}{ Boys } & \multicolumn{4}{|c|}{ Girls } \\
\hline & \multicolumn{2}{|l|}{ Model 1} & \multicolumn{2}{|l|}{ Model 2} & \multicolumn{2}{|c|}{ Model 3} & \multicolumn{2}{|c|}{ Model 4} \\
\hline & Coef. & $\mathrm{SE}$ & Coef. & $\mathrm{SE}$ & Coef. & SE & Coef. & SE \\
\hline $\begin{array}{l}\text { Maternal Education } \\
\text { (Ref. Lowest } 17 \% \text { of distribution) }\end{array}$ & & & & & & & & \\
\hline Middle educated & $0.15 * * *$ & 0.02 & $0.14 * * *$ & 0.02 & $0.15 * * *$ & 0.02 & $0.14 * * *$ & 0.02 \\
\hline Highest educated (top 21\%) & $0.51 * * *$ & 0.02 & $0.49 * * *$ & 0.03 & $0.51 * * *$ & 0.03 & $0.49 * * *$ & 0.03 \\
\hline Family Structure (Ref. two-parent family, & & & & & & & & \\
\hline Non-standard family & $-0.04 *$ & 0.02 & -0.01 & 0.02 & $-0.10 * * *$ & 0.02 & -0.03 & 0.02 \\
\hline Socioeconomic differences in penalty & & & & & & & & \\
\hline Non-standard X Mid educated mother & $-0.06 * *$ & 0.02 & $-0.06 *$ & 0.03 & $-0.05 *$ & 0.02 & $-0.07 *$ & 0.03 \\
\hline Non-standard X Higher educated mother & $-0.17 * * *$ & 0.04 & $-0.11 *$ & 0.06 & $-0.15 * * *$ & 0.04 & $-0.24 * * *$ & 0.05 \\
\hline NLSY97 cohort (Ref. 79 cohort) & $0.08 * * *$ & 0.01 & $0.07 *$ & 0.03 & $0.18 * * *$ & 0.01 & $0.19 * * *$ & 0.04 \\
\hline Interactions with cohort & & & & & & & & \\
\hline Middle educated X NLSY97 & & & 0.05 & 0.03 & & & 0.03 & 0.04 \\
\hline Highest educated X NLSY97 & & & 0.06 & 0.05 & & & 0.05 & 0.05 \\
\hline Non-standard family X NLSY97 & & & -0.05 & 0.03 & & & $-0.13 * *$ & 0.04 \\
\hline Non-stand. X mid-ed. mot. X NLSY97 & & & -0.03 & 0.05 & & & 0.01 & 0.05 \\
\hline Non-stand. X hi-ed. mot. X NLSY97 & & & $-0.15 *$ & 0.08 & & & $0.18 *$ & 0.08 \\
\hline Constant & 0.03 & 0.02 & 0.03 & 0.02 & $0.06 * *$ & 0.02 & $0.06 * *$ & 0.02 \\
\hline $\mathrm{N}$ & 6,783 & & 6,783 & & 7,018 & & 7,018 & \\
\hline
\end{tabular}

Controls included: age, region and ethnicity. Sample weights included. Standard errors clustered by original household. $* * * \mathrm{p}><0.001 ; * * \mathrm{p}<0.01$;

$* \mathrm{p}<0.05 ; \dagger \mathrm{p}<0.10$. 
Models 1 and 3 of Table 3 display to what extent there is heterogeneity in penalties between SES-groups. The penalty related to having lived in a non-standard family is greater for respondents with higher educated mothers as compared to those with lower educated mothers. Once looking at changes in heterogeneity across cohorts a contrast between boys and girls emerges. Model 2 shows how heterogeneity in penalties strengthened across cohorts for boys (as indicated by the three-way interaction effect of cohort with maternal education and family structure). In other words, the penalty related to having lived in a nonstandard family increased more strongly for boys with higher educated mothers than for boys with lower educated mothers.

Surprisingly, heterogeneity in penalties changed in the opposite direction for girls. Even though the penalty of having lived in a non-standard family increased by 13 percentage points for girls with lower educated mothers (i.e. the main interaction effect of family structure with cohort), it decreased with 5 percentage points for girls with higher educated mothers (i.e. -0.13 plus the 0.18 points of the interaction effect of family structure with cohort and maternal education). The next section quantifies and decomposes the joint contribution of these different trends to group differences in educational attainment.

\section{Decomposition analysis}

Table 4 displays the results of our decomposition analysis (employing the detailed family structure categories of Table 2 Model 1). We decompose changes over time in the educational attainment gap between individuals with higher educated and lower educated mothers. The first rows display the absolute gaps in bachelor degree attainment between both groups in 1979, which are congruent with those already observed before: 47.6 percentage points for boys and 46.1 points for girls. The second rows indicate the change in 
these gaps: increases of 2.5 and 12.5 percentage points for boys and girls, respectively. Component 3.i indicates the part of these changing gaps not explained by changes in the prevalence and penalties related to childhood family structures, whereas the components 3.ii to 3.v indicate the parts that did contribute to maternal education gaps in educational attainment. We discuss the contribution of each individual component separately.

\section{Effects of general changes in the prevalence of non-standard families}

Component 3.ii quantifies the contribution of the general increases in the prevalence of nonstandard families to the maternal education gap in education. Because penalties related to non-standard family structures are bigger for respondents with higher educated mothers, increases in the prevalence of non-standard families across cohorts have reduced maternal education gaps in attainment. For boys, this component (3.ii) was related to a 3.0 percentage point reduction in the gap, whereas this reduction was estimated at 2.5 points for girls.

\section{Effect of the changing parental SES gap in the prevalence of non-standard families}

Component 3.iii operationalizes the 'diverging destinies' argument regarding family structure in its simplest form. The gap in bachelor degree attainment between individuals with higher and lower educated mothers is estimated to have grown by 2.1 percentage points for men and by 2.5 percentage points for women due to the divergence in the prevalence of family structure types by maternal education. These correspond to a $4 \%$ and a $5 \%$ increase in the attainment gaps observed in 1979, respectively. 
Table 4. Decomposition analysis for various outcome variables and subsamples

\begin{tabular}{|c|c|c|c|c|c|c|}
\hline & \multicolumn{3}{|c|}{ Outcome } & \multicolumn{3}{|c|}{ Subsample (Bachelor Degree) } \\
\hline & Bachelor Degree & $\begin{array}{l}\text { High School } \\
\text { Degree }\end{array}$ & $\begin{array}{l}\text { Years of } \\
\text { Education }\end{array}$ & Black & Hispanic & $\begin{array}{c}\text { Non-Black / } \\
\text { Non-Hispanic }\end{array}$ \\
\hline \multicolumn{7}{|l|}{ Boys } \\
\hline Maternal Education Gap D in 1979 & 0.476 & 0.257 & 3.43 & 0.239 & 0.261 & 0.516 \\
\hline Change in Gap $\Delta \mathrm{D}$ & 0.025 & -0.070 & 0.46 & 0.202 & 0.176 & -0.015 \\
\hline 3.i: Changing intercept & 0.088 & -0.075 & 0.48 & 0.387 & 0.281 & 0.033 \\
\hline 3.ii: Changing Prevalence & -0.030 & 0.004 & -0.08 & -0.060 & -0.046 & -0.029 \\
\hline 3.iii: Changing Prevalence by SES & 0.021 & 0.006 & 0.15 & 0.018 & -0.010 & 0.025 \\
\hline 3.vi: Changing Penalties & 0.022 & -0.013 & 0.17 & 0.015 & -0.002 & 0.014 \\
\hline 3.v: Changing Penalties by SES & -0.075 & 0.007 & -0.26 & -0.158 & -0.048 & -0.058 \\
\hline Total Contribution (3.ii-3.v) & -0.063 & -0.005 & -0.02 & -0.185 & -0.105 & -0.048 \\
\hline Total Contribution as \% of Gap D in 1979 & -13.2 & -1.8 & -0.1 & -77.4 & -40.1 & -9.3 \\
\hline \multicolumn{7}{|l|}{ Girls } \\
\hline Maternal Education Gap D in 1979 & 0.461 & 0.227 & 3.24 & 0.246 & 0.248 & 0.492 \\
\hline Change in Gap $\Delta \mathrm{D}$ & 0.125 & -0.064 & 0.84 & 0.284 & 0.231 & 0.098 \\
\hline 3.i: Changing intercept & 0.056 & -0.114 & 0.22 & 0.245 & 0.326 & -0.008 \\
\hline 3.ii: Changing Prevalence & -0.025 & 0.014 & 0.01 & 0.003 & -0.066 & -0.019 \\
\hline 3.iii: Changing Prevalence by SES & 0.025 & 0.024 & 0.16 & 0.012 & -0.026 & 0.033 \\
\hline 3.vi: Changing Penalties & 0.009 & 0.009 & 0.05 & 0.046 & 0.026 & 0.003 \\
\hline 3.v: Changing Penalties by SES & 0.061 & 0.003 & 0.39 & -0.021 & -0.029 & 0.088 \\
\hline Total Contribution (3.ii-3.v) & 0.070 & 0.066 & 0.62 & 0.039 & -0.099 & 0.106 \\
\hline Total Contribution as \% of Gap D in 1979 & 15.2 & 22.2 & 19.1 & 15.9 & -38.3 & 21.5 \\
\hline
\end{tabular}

Note. Controls included are maternal education, age, region and ethnicity (latter excluded in subsample models). Sample weights included. D = Difference in outcome between individuals with higher - lower educated mothers in 1979; $\Delta \mathrm{D}$ Absolute change in difference D between 1997 and $1979 ; 3 . \mathrm{i}=$ Intercept Effect; $3.1 \mathrm{ii}=\mathrm{Due}$ to average change in prevalence of family structures; $3 . i i i=$ Due to change in socioeconomic prevalence differences; $3 . i v=$ Due to change over time in average penalties; $3 . v=$ Due to change 


\section{Effect of general changes in penalties}

Component 3.iv quantifies the contribution of average increases in the penalties related to childhood family structures across cohorts. Before, we observed that penalties increased substantially across cohorts. For boys, increasing penalties across cohorts are estimated to have increased the maternal education gap with 2.2 percentage points, or $5 \%$ of the initial gap in 1979. This contribution arises because non-standard families are more common among boys with lower educated mothers. The contribution of changes in effect sizes across cohorts is therewith equally important as changes in the stratification of family structures over time for boys. For girls, the corresponding estimate is 0.9 percentage points or $2 \%$ of the gap in 1979.

\section{Effect of changing heterogeneity in penalties by maternal education}

The final component 3.v indicates the contribution of differential changes across cohorts in penalties related to childhood family structure. Among boys, penalties related to having lived in a non-standard family increased for those with lower and higher educated mothers alike, but increases were much more pronounced among boys with higher educated mothers (Table 3). This trend is therefore estimated to have reduced the maternal education gap in degree attainment by 7.5 percentage points. For girls, in contrast, the penalties related to non-standard family structures only increased for those with lower educated mothers across cohorts. This trend increased the maternal education gap in years of education by 6.1 percentage points. These contributions correspond to $-16 \%$ and $13 \%$ of the initial maternal education gaps observed in 1979. 


\section{The overall contribution of changes in family structures to inequality in outcomes}

The four different components (3.ii-3.v) combined give an indication of how changes in the prevalence of family structures and related penalties contributed to maternal education gaps in years of education. For men, the overall contribution for men is estimated at a 6.1 percentage point reduction in the gap between maternal education groups or $13 \%$ of the initial gap in 1979. For women, all components together are estimated to have increased the maternal education gap in attainment by 6.6 percentage points, or $15 \%$ of the initial gap observed in 1979. In fact, changes in family structures and its related penalties explained $56 \%$ of the overall increase in the maternal education gap in educational attainment across cohorts for girls.

This contrast in results between boys and girls is primarily produced by component $3 . \mathrm{v}$ which reflects changes in heterogeneity in the penalties related to childhood family structures across cohorts. To illustrate this issue, Figure 5 displays how bachelor degree attainment developed across cohorts for the different groups studied in this article. The black lines indicate the educational attainment of individuals who lived in a two-parent family at age 17 , whereas the corresponding grey lines indicate attainment of their peers who lived in a non-standard family at age 17 .

Among all groups, but one, the gap in education between those who lived with two parents and those who did not increased across cohorts. This is particularly the case for boys with higher educated mothers (a 20.0 percentage point increase across cohorts). The exception consists of women with higher educated mothers where the gap between those who lived with two parents and those who did not decreased (with 5.8 percentage points) across cohorts. In other words, socioeconomically advantaged girls seem to be exempt from the general trend of increasing penalties related to growing up in a non-standard family. This has a major impact on maternal education gaps in Bachelor's degree attainment for girls. In 
the discussion, we will review possible explanations for these diverging trends in penalties between boys, girls, and socioeconomic groups.

Figure 5. Bachelor degree attainment by cohort, childhood family structure and maternal education

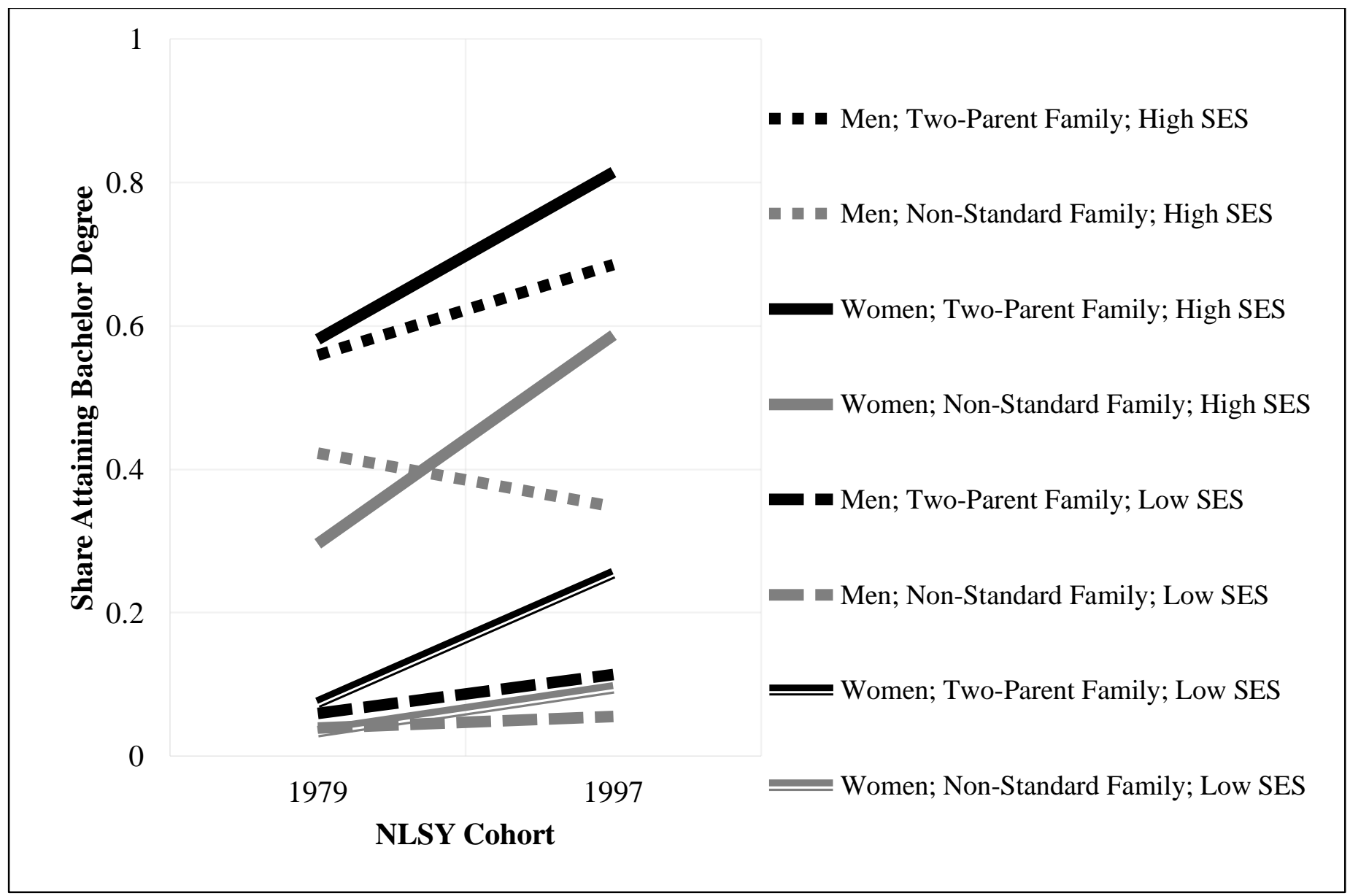

Note. Sample weights included. No controls. Low SES indicates having a lower educated mother, high SES indicates having a higher educated mother. Family Structure at age 17.

\section{Endogeneity}

Would our conclusions change if endogeneity could be accounted for? Previous research provides some indications as to whether endogeneity affects estimates for the two components that have been most influential in our analysis: the differential changes in the 
prevalence of family structures by maternal education (3.iii) and changes in the heterogeneity in effects by maternal education across cohorts (3.v).

Associations of childhood family structure with educational outcomes have been repeatedly found to overestimate actual causal effects (Härkönen et al. 2017; McLanahan et al. 2013). Many of the events marking the transition into non-standard family structures, such as separation or childbearing outside of a union, are driven by disadvantageous circumstances or related to factors such as conflict, stress or a lack of resources (Edin and Kafalas 2005; Lyngstad and Jalovaara 2010). It is therefore unlikely that selection into non-standard families is 'positive' and that the average penalties in our analysis underestimate actual causal effects. This would affect in particular component 3.iii regarding the differential change in the prevalence of childhood family structure across cohorts (this component depends on the average associations of childhood family structure with educational attainment). Therefore, estimates for this component should be regarded as upper-bound estimates. This might weaken the overall conclusion for girls but strengthen the conclusion for boys.

We can be relatively confident that endogeneity is not driving the results for changes over time in the heterogeneity in penalties by maternal education (component 3.v). Maternal education differences in penalties were similar for boys and girls in the 1979 cohort but changed in opposite directions for the 1997 cohort (See Table 3). Gender differences in effects (and trends therein) are complicated to explain based on endogeneity as boys and girls generally share the same families. ${ }^{7}$ Hence, explanations for these patterns have to concentrate on how men and women react differently to childhood family structures (and/or the determinants of childhood family structure). An issue we return to in the discussion. 


\section{Robustness Checks and Replication using the General Social Survey}

Table 4 summarizes the outcome of several replications of the main result once studying alternative outcomes and focusing on subsamples. Firstly, results are similar once looking at other measures of educational attainment for girls. The inequality amplifying effect of changing family structures is slightly stronger for high school completion and years of education than for bachelor degree completion. For boys, the equalizing contribution of changes in family structures is not visible for high school completion and years of education. This is primarily due to the (relative) absence of heterogeneity in penalties by maternal education for these educational outcomes, and in particular for high school completion. In other words, the impact of growing up in a non-standard family on high school completion is similar for boys from lower and higher educational backgrounds.

Once looking at different subsamples, it appears that changes in family structures particularly contributed to maternal education differences in bachelor degree attainment among Black girls, followed by Non-Black/Non-Hispanic girls. The main deviation from our main results is observed for Hispanic girls, for whom an equalizing influence of family structure changes is found. Changes in family structure particularly reduce maternal education differences in attainment among boys from ethnic minorities. This result arises because especially Black and Hispanic boys with higher educated mothers are increasingly affected by having lived in a household with a non-standard family structure. It has to be noted that cell sizes are small for some of the subsamples studied here (minimum cell size is 45 cases for Hispanic girls with higher educated mothers from the 1997 cohort) and results therefore primarily serve as an illustration that family structure might play a different role depending on race/ethnicity (Cross forthcoming). 
Results reported in Online Appendix D show how the main result of Table 4 is robust to using a) absolute instead of relative levels of maternal education, b) using multiple imputations of missing information, and c) fathers' education instead of mothers' education (while also using multiple imputations; results are weaker in this latter specification).

We aimed to replicate our analysis using the General Social Survey, but sample sizes appeared too limited to come to firm results. In the GSS, differences in Bachelor's Degree attainment between children who lived in a non-standard and children who lived in a twoparent family increased across cohorts too, and in particular among boys with higher educated mothers. However, girls with higher educated mothers are not exempt from the general increase in penalties related to having lived in a non-standard family in the GSS data. However, changes in penalties studied were not statistically significant for any of the groups studied due to the small sample size, refraining us from drawing conclusions based on this additional analysis. Results using the GSS and more information are provided in Online Appendix D.

\section{DISCUSSION}

Fifteen years ago, Sara McLanahan (2004) directed scholarly attention toward 'diverging destinies': several trends related to the second demographic transition intensified socialclass disparities in family resources. As the first generations of children whose families experienced these changes have come of age, we asked the question to what extent changes in childhood family structures translated into increased socioeconomic background inequalities in final educational attainment. We used data from the NLSY to compare a cohort that primarily grew up in two-parent families to a cohort where half of the respondents lived in a non-standard family at age 17. Decomposition analyses revealed that changes in family structure indeed increased maternal education differences in bachelor 
degree attainment by $15 \%$ for girls, but reduced inequalities in attainment by $13 \%$ for boys. Hence, we argue that the validity of the argument that changing family structures contributed to 'diverging destinies' varies by gender. For the observation period we studied, its applicability appears limited to girls.

The results of this paper neither support a general narrative that family structure changes have intensified socioeconomic inequality of opportunity, nor do they support earlier findings that its influence is small to negligible (Alamillo 2016; Bernardi and Boertien 2017; Duncan et al. 2017). These differences in conclusions can be primarily attributed to the lack of attention for heterogeneous effects by socioeconomic background (Duncan et al. 2017) and gender (Alamillo 2016; Bernardi and Boertien 2017) in earlier research (See Cooper and Pugh 2020 for a similar argument). How did including these considerations lead to conclusions that differ from those of earlier research?

In our results, the penalty related to having lived in a non-standard family increased across cohorts for all groups studied with the exception of girls with higher educated mothers. This trend appeared to be the most important contributor to the increasing maternal education gap in years of education among girls. In contrast, boys from higher educated backgrounds showed the greatest increases in penalties related to having lived in a non-standard family. This process narrowed down the socioeconomic background gap in educational attainment across cohorts among boys. How can these gender differences in how penalties changes across cohorts be explained?

The observation that penalties increased among socioeconomically advantaged boys can be aligned with previous research which suggested that individuals from advantaged backgrounds have 'more to lose' from living in a non-standard family (Biblarz and Raferty 1999; Bloome 2017; Coleman 1988; Martin 2012). The transmission of human capital from 
parents to children is more complicated for parents not residing with their children in the same household. If time-intensive parenting strategies have become more important for educational outcomes over time (Kalil, Ryan, and Corey 2012; Lareau 2002), obstacles toward intensive parenting, such as being the only co-resident parent, will have increasingly larger effects on outcomes. A similar argument can be made for the transmission of advantage through economic pathways. If educational attainment increasingly depends on the economic resources of parents (Duncan et al. 2017; Pfeffer 2018; Schneider et al., 2018), events that reduce parental income and wealth, such as parental separation, might have become increasingly consequential over time (Bernardi and Boertien 2016).

However, boys and girls grow up in the same households. If boys from higher socioeconomic backgrounds have 'more to lose' from not co-residing with both parents, why are socioeconomically advantaged girls not affected in the same way? Earlier research on the gender gap in educational attainment provides guidance for a possible interpretation of this result. These studies have documented how the outcomes of men depend more on the academic environment at school and at home than the outcomes of women (Autor et al. 2019; Buchmann and DiPrete 2006; Brenøe and Lundberg 2017; Chetty et al. 2016; Legewie and DiPrete 2012) and how the importance of fathers' education for men's outcomes has increased over time (Buchmann and DiPrete 2006). Possible explanations for this greater importance of the environment at home and at school relate to the construction of gender identities, with larger variation in how important academic achievement is for masculine identities than for feminine identities (DiPrete and Buchmann 2013; Legewie and DiPrete 2012). Hence, the resources of two-parent families that make it easier to create an academic environment at home might be less important for girls' educational attainment as compared to boys' attainment. 
A main takeaway point from this article is therefore that the mechanisms through which parents transmit their advantage to their offspring differ systematically according to gender. For men, the transmission depends to an important extent on resources that two-parent families more easily provide such as intensive parenting, economic resources and (therefore) an academically stimulating environment (Amato 2010; Bernardi and Boertien 2016; Brand et al. 2019b). The big question for future research is which mechanisms characterize the transmission of advantage from parents to their female children. To answer this question, further research can look more closely at how girls from advantaged backgrounds overcome the obstacles to educational attainment when living in a non-standard family.

Our results also speak to the debate on the gender reversal in educational attainment. The argument that changes in family structures can explain the reversal in the gender gap has been challenged by previous research. Lundberg (2017) used Add Health data to look at the educational attainment of respondents born from 1976 to 1984 and found that the effects of family structure on educational attainment do not differ by gender. In line with these results, we also did not find gender differences in family structure effects on average across cohorts and socioeconomic groups. But, our analysis did find important gender differences once looking at differences within parental education groups. Gender differences in education increased among all groups considered, but they were the most pronounced among socioeconomically advantaged children who lived in non-standard family structures. Within this group, the gender gap reversed from a 12.7 percentage point advantage for boys to a 23.9 percentage point advantage for girls across cohorts. In comparison, among socioeconomically advantaged children in two-parent families, there was a 2.2 percentage point advantage for girls in the 1979 cohort which rose to a 12.9 percentage point advantage for girls in the 1997 cohort. Therefore, the changes in how socioeconomically advantaged 
boys and girls react to growing up in a non-standard family contribute to the female advantage in education.

We would like to highlight three major limitations of our analysis. Firstly, it could be that the time span considered here is not long enough to capture the complete impact of changes in the stratification of family structures. Even though maternal education differences in the prevalence of non-standard families increased considerably across the two cohorts studied here, a 15 percentage-point difference between groups already existed in 1979 (See Figure 3). Therefore, in additional analysis, we estimated the cross-sectional contribution of nonstandard families to the maternal education gap in years of education in 1997 (See Online Appendix E). For this analysis, we applied a modified Blinder-Oaxaca approach to simulate how high socioeconomic background differences would be if all individuals were to grow up in a two-parent family. Similar to our main results, these simulations indicate that the maternal education gap in bachelor attainment would be 5 percentage points lower than observed in 1997 for boys, but 15 percentage points higher for girls.

Secondly, a limitation of our study has been that we were not able to account for all sources of endogeneity. For several parts of our analysis, we could make reasonable assumptions about causality or as to whether our estimates could be regarded as under or overestimations of (differences in) the penalties related to childhood family structure, but for other parts, we could not. Even though the components for which this was not possible appeared of relatively little importance for our conclusions (i.e. changes over time in average childhood family structure penalties and the cross-cohort average of socioeconomic differences in penalties contributed little to changes in education gaps), their importance could change if endogeneity were to be accounted for. Nonetheless, the analysis pointed at changes over time in the heterogeneity in penalties by maternal education as the major driver of results. Even though gender differences in these trends make it unlikely that these patterns are 
driven by selection into family structure types, there is one possibility that cannot be excluded. If men and women react differently to factors that both determine changes over time in the selection of families into non-standard forms and educational attainment, endogeneity might still play a role. In that case, explanations would have to be based on why girls from socioeconomically advantaged backgrounds react differently to the determinants of living in a non-standard family as compared to boys from advantaged backgrounds and as compared to girls from disadvantaged backgrounds.

Finally, data limitations prevented us from taking into account more complex family structure trajectories, as well as the number of family transitions experienced during childhood; a factor that has received increasing attention in the literature (Cavanagh and Fomby 2019). Children from the 1997 cohort who lived in a non-standard family at age 17 are more likely to have experienced several family structure transitions than children who lived in a non-standard family from the 1979 cohort (Brown et al. 2016). This might explain why, in general, the penalty related to having lived in a non-standard family increased across cohorts. However, the number of family transitions increased especially among children from lower socioeconomic backgrounds (Brown et al. 2016), but increases in effect sizes were most pronounced for socioeconomically advantaged boys. Furthermore, additional analysis looking at more complex family structure trajectories for the 1979 cohort (See Online Appendix A) did not show larger penalties related to trajectories involving at least 2 transitions than trajectories with at most 1 transition. Future research can further refine our results once more detailed information on childhood family structure trajectories is available. But, given that our results appear to be primarily driven by gender differences in how socioeconomically advantaged children are affected by growing up in a non-standard family, explanations for our conclusions are likely to lie elsewhere (because both boys and girls experienced increases in the number of family transitions experienced). 
To conclude, the results of this paper are difficult to align with a general argument that changes in family structure have increased socioeconomic background inequality in educational attainment. Socioeconomic differences in the penalty related to childhood family structure undermine the argument that the increasing social stratification of family structure types has led to 'diverging destinies', at least in terms of final educational attainment. In the case of men, our results are in line with the argument proposed by Coleman in 1988 that non-standard family structures pose challenges to the transmission of advantage from parents to children. Conversely, for women, we do find that family structure contributes to 'diverging destinies'. A major task for future research will be to investigate the mechanisms underlying gender differences in the applicability of the argument that changes in family structures led to 'diverging destinies'. More in general, the results of this paper underline that how different social groups deal with given disadvantageous events and situations (i.e. heterogeneity in penalties) is equally important for understanding inequality of opportunity as understanding why the prevalence of such events and situations are socioeconomically stratified. Most existing research has focused on the latter important factor (McLanahan and Percheski 2008), and we hope that this paper will trigger more research on how people deal with events and situations too.

\section{ENDNOTES}

1. Replication files including a 'tagset' to download the data from the NLS Investigator and a STATA do-file for all data management and analysis are available as an online appendix.

2. We replicated the analysis using paternal education combined with multiple imputations of cases with missing information. Findings are robust; see "Robustness Checks". 
3. These cut-offs were chosen to make shares falling into the different groups across cohorts as similar as possible. Robustness checks using absolute levels of education were run. See "Robustness Checks".

4. The survey asks the responding parent about childhood family structure histories in Wave 1 but only if the child ever lived without the responding parent. Relationship histories are collected from the responding parent but only cover marriages. As our analysis relies on estimating heterogeneous effects of family structures by parental SES, using patchy retrospective information runs the risk of introducing biases due to factors such as SES-differences in the prevalence of cohabiting unions, which are not recorded.

5. See Online Appendix A

6. The $\beta$ 's are estimated by running four separate OLS regression models, one for each group and cohort. Covariates are included using effect coding for categorical variables (i.e. one dummy for each category with the reference categories taking on the value of -1 instead of the value 0 ) to avoid choices of reference categories to affect the decomposition results (Jann, 2008:9). Our approach differs slightly from Kim's in that we do not apply the averaging method for coefficients (Kim, 2010:627) in the case of our main mediating variable: family structure. In the case of family structure, we use having lived in a two-parent family as the reference category, $\sum$ stherefore sums over the various non-standard family structures where betas indicate the effect with two-parent families as the reference. In our approach, we therefore quantify changes over time in the cross-sectional contribution of the presence of non-standard families to group differences in outcomes. In other words, the constants of term 3.i indicate estimated attainment if all individuals of that group were to have lived with two parents. Using effect coding also for family structure 
would calculate a counterfactual that might be well-suited for quantifying changes in discrimination (i.e. the goal of Kim's approach), but has a less clear interpretation in our case. See Online Appendix B for a more detailed explanation.

7. One might argue that the gender of children could affect family structure transitions. We aimed to look into this issue by estimating sibling-fixed effects models, as some respondents of the survey originate from the same households. These fixed-effects models revealed very similar and statistically significant interaction effects between gender, family structure, and maternal education as compared to OLS models (Online Appendix C).

\section{REFERENCES}

Alamillo, Julia. 2016. "Family Structure and the Reproduction of Inequality: A Decomposition Approach." Mathematica Policy Research Working Paper 49. https://www.mathematica.org/-/media/publications/pdfs/family_support/2016/familystructure-wp49.pdf

Amato, Paul R. 2000. "The consequences of divorce for adults and children." Journal of Marriage and Family 62 (4): 1269-1287.

Amato, Paul R. 2001. "Children of divorce in the 1990s: an update of the Amato and Keith (1991) meta-analysis.” Journal of Family Psychology, 15(3): 355-370.

Amato, Paul R. 2001. "Research on divorce: Continuing trends and new developments. Journal of Marriage and Family” 72(3): 650-666.

Augustine, Jennifer March. 2014. "Maternal education and the unequal significance of family structure for children's early achievement.” Social Forces 93(2): 687-718. 
Autor, David, Figlio, David, Karbownik, Krzysztof, Roth, Jeffrey and Wasserman, Melanie. 2019. "Family Disadvantage and the Gender Gap in Behavioral and Educational Outcomes. ” American Economic Journal: Applied Economics 11(3): 338-381.

Baron, Reuben M. and David A. Kenny. 1986. "The moderator-mediator variable distinction in social psychological research: Conceptual, strategic, and statistical considerations." Journal of personality and social psychology 51(6): 1173.

Bernardi, Fabrizio and Diederik Boertien. 2016. "Understanding Heterogeneity in the Effects of Parental Separation on Educational Attainment in Britain: Do Children from Lower Educational Backgrounds Have Less to Lose?” European Sociological Review 32(6): 807-819.

Bernardi, Fabrizio and Diederik Boertien. 2017. "Non-intact families and diverging educational destinies: A decomposition analysis for Germany, Italy, the United Kingdom and the United States.” Social Science Research 63: 181-191.

Bertrand, Marianne, and Jessica Pan. 2013. "The trouble with boys: Social influences and the gender gap in disruptive behavior." American Economic Journal: Applied Economics 5(1): 32-64.

Biblarz, Timothy J., and Adrian E. Raftery. 1999. "Family structure, educational attainment, and socioeconomic success: Rethinking the" pathology of matriarchy"." American Journal of Sociology 105 (2): 321-365.

Bloome, Deirdre. 2014. "Racial inequality trends and the intergenerational persistence of income and family structure." American Sociological Review 79(6): 1196-1225.

Bloome, Deirdre. 2017. "Childhood family structure and intergenerational income mobility in the United States." Demography 54 (2): 541-569. 
Brady, David, Ryan M. Finnigan, and Sabine Hübgen. 2017. "Rethinking the risks of poverty: A framework for analyzing prevalences and penalties." American Journal of Sociology 123(3): 740-786.

Brand, Jennie E., Ravaris Moore, Xi Song, and Yu Xie. 2019. "Parental divorce is not uniformly disruptive to children's educational attainment." Proceedings of the National Academy of Sciences 116 (15): 7266-7271.

Brand, Jennie E., Ravaris Moore, Xi Song, and Yu Xie. 2019. "Why does parental divorce lower children's educational attainment? A causal mediation analysis." Sociological Science, 6: 264-292.

Brenøe, Anne Ardila, and Shelly Lundberg. 2018. "Gender gaps in the effects of childhood family environment: Do they persist into adulthood?." European Economic Review 109: 42-62.

Brown, Susan L., J. Bart Stykes, and Wendy D. Manning. 2016. "Trends in children's family instability, 1995-2010." Journal of Marriage and Family, 78 (5): 1173-1183.

Buchmann, Claudia, and Thomas A. DiPrete. 2006. "The growing female advantage in college completion: The role of family background and academic achievement." American Sociological Review 71 (4): 515-541.

Bzostek, Sharon H., and Lawrence M. Berger. 2017. "Family structure experiences and child socioemotional development during the first nine years of life: Examining heterogeneity by family structure at birth." Demography 54 (2): 513-540.

Cavanagh, Shannon E., and Paula Fomby. 2019. "Family instability in the lives of American children." Annual Review of Sociology, 45: 493-513.

Cherlin, Andrew J. 1999. "Going to extremes: Family structure, children's well-being, and social science." Demography 36 (4): 421-428. 
Cherlin, Andrew J. 2014. Labor's Love Lost: The Rise and Fall of the Working-Class Family in America. New York: Russell Sage Foundation.

Chetty, Raj, Nathaniel Hendren, Frina Lin, Jeremy Majerovitz, and Benjamin Scuderi. 2016. "Childhood environment and gender gaps in adulthood." American Economic Review 106 (5): 282-88.

Coleman, James S. 1988 "Social capital in the creation of human capital." American journal of sociology, 94: S95-S120.

Cooper, Marianne, and Allison J. Pugh. 2020. "Families across the income spectrum: A decade in review." Journal of Marriage and Family 82 (1): 272-299.

Cross, Christina, J. .Forthcoming. Racial/Ethnic Differences in the Association Between Family Structure and Children's Education. Journal of Marriage and Family. https://doi.org/10.1111/jomf.12625

DiPrete, Thomas A. and Claudia Buchmann. 2013. The Rise of Women: The Growing Gender Gap in Education and What it Means for American Schools. New York: Russell Sage Foundation.

Duncan, Greg J., Ariel Kalil, and Kathleen M. Ziol-Guest. 2017. "Increasing inequality in parent incomes and children's schooling." Demography 54 (5): 1603-1626.

Edin, Kathryn, and Maria Kefalas. 2005. Promises I can keep: Why poor women put motherhood before marriage. University of California Press.

Ellwood, David T., and Christopher Jencks. 2004. "The uneven spread of single-parent families: What do we know? Where do we look for answers." In: Neckerman, Kathryn (ed.) Social inequality. New York: Russell Sage Foundation.

Esping-Andersen, Gøsta. 2007. "Sociological explanations of changing income distributions." American Behavioral Scientist, 50(5): 639-658. 
Fomby, Paula, and Andrew J. Cherlin. "Family instability and child well-being." American Sociological Review 72 (2): 181-204.

Fomby, Paula, and Cynthia Osborne. 2017. "Family instability, multipartner fertility, and behavior in middle childhood." Journal of Marriage and Family 79 (1): 75-93.

Härkönen, Juho, Fabrizio Bernardi, and Diederik Boertien. 2017. "Family Dynamics and Child Outcomes: An Overview of Research and Open Questions" European Journal of Population 33(2): 163-184.

Härkönen, Juho and Jaap Dronkers. 2006. "Stability and change in the educational gradient of divorce. A comparison of seventeen countries." European Sociological Review, 22(5): 501-517.

Kalil, Ariel, Rebecca Ryan, and Michael Corey. 2012. "Diverging destinies: Maternal education and the developmental gradient in time with children." Demography 49 (4): $1361-1383$.

Kalmijn, Matthijs. 2010 "Racial differences in the effects of parental divorce and separation on children: Generalizing the evidence to a European case." Social Science Research 39 (5): 845-856.

Kalmijn, Matthijs, Anneke Loeve, and Dorien Manting. 2007. "Income dynamics in couples and the dissolution of marriage and cohabitation." Demography, 44 (1): 159-179.

Kim, ChangHwan. 2010. "Decomposing the change in the wage gap between White and Black men over time, 1980-2005: An extension of the blinder-Oaxaca decomposition method." Sociological Methods \& Research 38 (4): 619-651.

Lareau, Annette. 2002. "Invisible inequality: Social class and childrearing in black families and white families." American Sociological Review 67 (5): 747-776. 
Lee, Dohoon, and Sara McLanahan. 2015. "Family structure transitions and child development: Instability, selection, and population heterogeneity." American Sociological Review 80 (4): 738-763.

Legewie, Joscha, and Thomas A. DiPrete. 2012. "School context and the gender gap in educational achievement." American Sociological Review 77 (3): 463-485.

Lundberg, Shelly J. 2017. "Father Absence and the Educational Gender Gap." IZA Discussion Paper, No. 10814. Available at SSRN: https://ssrn.com/abstract=2979961

Lyngstad, Torkild Hovde, and Marika Jalovaara. 2010. "A review of the antecedents of union dissolution." Demographic Research 23: 257-292.

Magnuson, Katherine, and Lawrence M. Berger. 2009. "Family structure states and transitions: Associations with children's well-being during middle childhood." Journal of Marriage and Family 71 (3): 575-591.

Mariani, Elena, Berkay Özcan, and Alice Goisis. 2017 "Family trajectories and well-being of children born to lone mothers in the UK." European Journal of Population 33 (2): $185-215$.

Martin, Steven P. 2006. "Trends in marital dissolution by women's education in the United States." Demographic research 15: 537-560.

Martin, Molly A. 2012. "Family structure and the intergenerational transmission of educational advantage." Social Science Research 41 (1): 33-47.

Matysiak, Anna, Marta Styrc, and Daniele Vignoli. 2014. "The educational gradient in marital disruption: A meta-analysis of European research findings." Population Studies, 68 (2): 197-215.

McLanahan, Sara. 2004. "Diverging destinies: How children are faring under the second demographic transition." Demography 41 (4): 607-627. 
McLanahan, Sara and Wade Jacobsen. 2015. Diverging destinies revisited. In: Amato et al. (Eds.) Families in an era of increasing inequality. Springer International Publishing.

McLanahan, Sara, and Christine Percheski. 2008. "Family structure and the reproduction of inequalities." Annual Review of Sociology 34: 257-276.

McLanahan, Sara and Gary Sandefur. 1994. Growing up with a Single Parent, What Hurts, What Helps. Cambridge, MA: Harvard University Press.

McLanahan, Sara, Laura Tach, and Daniel Schneider. "The causal effects of father absence." Annual review of sociology 39: 399-427.

Pfeffer, Fabian T. 2018. Growing wealth gaps in education. Demography, 55: 1033-1068.

Pryor, Jan and Bryan Rodgers. 2001. Children in changing families. Life after parental separation. Blackwell Publishers.

Putnam, Robert D. 2016. Our kids: The American dream in crisis. Simon and Schuster.

Rackin, Heather M., and Christina M. Gibson-Davis. 2018. "Social class divergence in family transitions: The importance of cohabitation." Journal of Marriage and Family 80 (5): 1271-1286.

Schneider, Daniel, Orestes P. Hastings, and Joe LaBriola. 2018. "Income inequality and class divides in parental investments." American Sociological Review, 83 (3): 475-507.

Seltzer, Judith A. 2000. Child support and child access: Experiences of divorced an nonmarital families. In: J. Thomas Oldham and Marygold Shire Melli (Eds.) Child Support: The Next Frontier. Ann Arbor: University of Michigan Press.

Smock, Pamela J., and Christine R. Schwartz. 2020. "The demography of families: A review of patterns and change." Journal of Marriage and Family 82 (1): 9-34.

Thomson, Elizabeth, Thomas L. Hanson, and Sara S. McLanahan. 1994 "Family structure and child well-being: Economic resources vs. parental behaviors." Social Forces 73 (1): 221-242. 
Thomson, Elizabeth, Trude Lappegård, Marcia Carlson, Ann Evans, and Edith Gray. 2014. "Childbearing across partnerships in Australia, the United States, Norway, and Sweden." Demography 51(2): 485-508.

Waldfogel, Jane, Terry-Ann Craigie and Jeanne Brooks-Gunn. 2010. Fragile families and child wellbeing. Future of Children, 20(2): 87-112.

Western, Bruce, Deirdre Bloome, and Christine Percheski. 2008. "Inequality among American families with children, 1975 to 2005." American Sociological Review 73 (6): 903-920. 
Online Appendix A. Analysis using simple and more fine-grained childhood family structure trajectories for the 1979 cohort.

Table A1. OLS regressions explaining bachelor degree attainment for 1979 cohort based on a more detailed measure of family structure trajectories up until age 18

\begin{tabular}{|c|c|c|c|c|}
\hline & $\mathrm{M}$ & & Won & \\
\hline & Mod & & Mod & \\
\hline & Coef. & SE & Coef. & SE \\
\hline Family structure trajectory at age 18 & & & & \\
\hline Lived with both biological parents $0-18$ years (ref.) & & & & \\
\hline Both parents at birth, separation, never a step-parent & $-0.06^{*}$ & 0.02 & $-0.14 * * *$ & 0.02 \\
\hline Both parents at birth, separation, ever a step-parent & $-0.11 * * *$ & 0.03 & $-0.15^{* * *}$ & 0.02 \\
\hline Single parent at birth, never a step-parent & -0.03 & 0.06 & -0.07 & 0.05 \\
\hline Single parent at birth, ever a step-parent & -0.02 & 0.03 & $-0.12 * * *$ & 0.04 \\
\hline Parent died before 1981 & $-0.05^{\dagger}$ & 0.03 & -0.03 & 0.03 \\
\hline One parent moved in after birth and moved out again later & -0.07 & 0.05 & $-0.20 * * *$ & 0.05 \\
\hline One parent moved in after birth and never left & -0.09 & 0.07 & $-0.13^{\dagger}$ & 0.07 \\
\hline Constant & 0.03 & 0.02 & $0.08 * * *$ & 0.02 \\
\hline $\mathrm{N}$ & 3,612 & & 3,774 & \\
\hline
\end{tabular}

Note. Family structure variables measured at age 18 instead of 17, based on retrospectively reported co-residence with biological father, biological mother, and eventual step-parents at each age. Parental death is recorded in the 1981 wave, and therefore measured at various ages (15-23 yearsold). If one parent had died in 1981, an individual entered this category regardless of other family structure transitions experienced. Controls included are maternal education, age, region and ethnicity. Sample weights included. 
Table A2. Distribution of detailed family structure trajectory types across maternal education groups for 1979 cohort (shares)

\section{Family structure at age 18}

Lived with both biological parents $0-18$ years

Both parents at birth, separation, never a step-parent

Both parents at birth, separation, ever a step-parent

Single parent at birth, never a step-parent

$\begin{array}{lll}\text { Lower } & \text { Middle } & \text { Higher } \\ \text { Educated } & \text { Educated } & \text { Educated } \\ \text { Mother } & \text { Mother } & \text { Mother }\end{array}$

Single parent at birth, ever a step-parent

$\begin{array}{lll}0.61 & 0.69 & 0.75\end{array}$

$0.14 \quad 0.11 \quad 0.11$

Parent died before 1981

$\begin{array}{lll}0.07 & 0.08 & 0.06\end{array}$

One parent moved in after birth and moved out again later

$\begin{array}{lll}0.03 & 0.01 & 0.01\end{array}$

One parent moved in after birth and never left

$\begin{array}{lll}0.02 & 0.02 & 0.01\end{array}$

$\begin{array}{lll}0.11 & 0.06 & 0.05\end{array}$

$\begin{array}{lll}0.01 & 0.02 & 0.01\end{array}$

$\begin{array}{lll}0.01 & 0.01 \quad 0.00\end{array}$

\section{As percentage of non-standard families}

Both parents at birth, separation, never a step-parent

$35.9 \quad 35.5 \quad 44.0$

Both parents at birth, separation, ever a step-parent

Single parent at birth, never a step-parent

7.7

Single parent at birth, ever a step-parent

3.2

Parent died before 1981

$\begin{array}{lll}5.1 & 6.5 & 4.0\end{array}$

One parent moved in after birth and moved out again later

One parent moved in after birth and never left

2.6

6.5

4.0

2.6

3.2

0.0

$\mathrm{N}$

1,842

4,294

1,250

Sample weights included, no controls 
Table A3. Cross-sectional decomposition with original variables used

\begin{tabular}{|c|c|c|c|c|}
\hline & \multicolumn{2}{|l|}{ Men } & \multicolumn{2}{|l|}{ Women } \\
\hline & Coef. & SE & Coef. & SE \\
\hline Actual difference (high-low educated mothers) & $0.476 * * *$ & 0.02 & $0.461 * * *$ & 0.02 \\
\hline Difference due to prevalence: controls & $0.016^{\dagger}$ & 0.01 & $0.019^{*}$ & 0.01 \\
\hline Difference due to penalties: controls & $0.124 * * *$ & 0.02 & $0.099 * *$ & 0.03 \\
\hline Difference net of controls & 0.336 & & 0.343 & \\
\hline $\begin{array}{l}\text { Difference due to socioeconomic differences in } \\
\text { prevalence of family structure: Total }\end{array}$ & $0.009^{*}$ & 0.00 & $0.024 * * *$ & 0.01 \\
\hline Step-parent families & 0.001 & 0.00 & $0.006 \%$ & 0.00 \\
\hline Single-parent families & 0.002 & 0.00 & 0.003 & 0.00 \\
\hline Other family forms & $0.005 *$ & 0.00 & $0.014 * * *$ & 0.00 \\
\hline $\begin{array}{l}\text { Difference due to socioeconomic differences in } \\
\text { penalties of family structure: Total }\end{array}$ & -0.022 & 0.02 & $-0.064 * * *$ & 0.01 \\
\hline Step-parent families & -0.006 & 0.01 & $-0.021 * * *$ & 0.01 \\
\hline Single-parent families & -0.007 & 0.01 & $-0.020^{*}$ & 0.01 \\
\hline Other family forms & -0.009 & 0.01 & $-0.023 * * *$ & 0.01 \\
\hline Total accounted for by family structure & -0.014 & & -0.040 & \\
\hline As \% of actual background difference & -2.9 & & -7.6 & \\
\hline As \% of background difference net of controls & -4.2 & & -11.7 & \\
\hline $\mathrm{N}$ & 1,519 & & 1,594 & \\
\hline
\end{tabular}

Controls included are maternal education, age, region and ethnicity. Sample weights included. 
Table A4. Cross-sectional decomposition with more fine-grained variables used

\begin{tabular}{|c|c|c|c|c|}
\hline & \multicolumn{2}{|l|}{ Men } & \multicolumn{2}{|l|}{ Women } \\
\hline & Coef. & SE & Coef. & SE \\
\hline Actual difference (high-low educated mothers) & $0.478 * * *$ & 0.02 & $0.461 * * *$ & $\mathbf{0 . 0 2}$ \\
\hline Difference due to prevalence: controls & $0.015^{+}$ & 0.01 & $0.019^{*}$ & 0.01 \\
\hline Difference due to penalties: controls & $0.124 * * *$ & 0.02 & $0.099 * *$ & 0.03 \\
\hline Difference net of controls & 0.339 & & 0.343 & \\
\hline $\begin{array}{l}\text { Difference due to socioeconomic differences in } \\
\text { prevalence of family structure: Total } \\
\text { Lived with both biological parents } 0-18 \text { years (ref.) }\end{array}$ & 0.005 & 0.00 & $0.021 * * *$ & 0.01 \\
\hline Both parents at birth, separation, never a step-parent & 0.001 & 0.00 & 0.005 & 0.00 \\
\hline Both parents at birth, separation, ever a step-parent & 0.000 & 0.00 & $0.006 \%$ & 0.00 \\
\hline Single parent at birth, never a step-parent & -0.001 & 0.00 & 0.002 & 0.00 \\
\hline Single parent at birth, ever a step-parent & 0.001 & 0.00 & $0.003 \%$ & 0.00 \\
\hline Parent died before 1981 & 0.003 & 0.00 & $0.005 \%$ & 0.00 \\
\hline One parent moved in after birth and moved out again later & -0.000 & 0.00 & -0.001 & 0.00 \\
\hline One parent moved in after birth and never left & 0.001 & 0.00 & 0.000 & 0.00 \\
\hline $\begin{array}{l}\text { Difference due to socioeconomic differences in } \\
\text { penalties of family structure: Total }\end{array}$ & -0.012 & 0.02 & $-0.062 * * *$ & 0.02 \\
\hline Lived with both biological parents 0-18 years (ref.) & & & & \\
\hline Both parents at birth, separation, never a step-parent & -0.003 & 0.01 & $-0.028 * *$ & 0.01 \\
\hline Both parents at birth, separation, ever a step-parent & -0.007 & 0.01 & $-0.018^{* *}$ & 0.01 \\
\hline Single parent at birth, never a step-parent & 0.003 & 0.00 & $-0.006 * *$ & 0.00 \\
\hline Single parent at birth, ever a step-parent & -0.003 & 0.00 & $-0.006^{*}$ & 0.00 \\
\hline Parent died before 1981 & -0.003 & 0.01 & -0.004 & 0.01 \\
\hline One parent moved in after birth and moved out again later & 0.002 & 0.00 & -0.001 & 0.00 \\
\hline One parent moved in after birth and never left & -0.000 & 0.00 & $-0.001^{*}$ & 0.00 \\
\hline Total accounted for by family structure & -0.007 & & -0.041 & \\
\hline As \% of actual background difference & -1.4 & & -8.9 & \\
\hline As $\%$ of background difference net of controls & -2.1 & & -12.0 & \\
\hline $\mathrm{N}$ & 1,509 & & 1,594 & \\
\hline
\end{tabular}

Note. Family structure variables measured at age 18 instead of 17, based on retrospectively reported co-residence with biological father, biological mother, and eventual step-parents at each age. Parental death is recorded in the 1981 wave, and therefore measured at various ages (15-23 yearsold). If one parent had died in 1981, an individual entered this category regardless of other family structure transitions experienced. Controls included are maternal education, age, region and ethnicity. Sample weights included. 
Online Appendix B. Blinder-Oaxaca Decomposition Approach for Changes Over Time

In this appendix we provide more information on the method employed in our article "Gendered diverging destinies: Changing family structures and inequality of opportunity among boys and girls in the United States". In our analysis, we use an extended BlinderOaxaca decomposition approach (Kim, 2010; Smith \& Welch, 1989) to estimate how much family structure changes across the two cohorts considered here contributed to inequality in educational outcomes by parental SES. In a cross-sectional setting, the Blinder-Oaxaca decomposition approach decomposes the absolute difference (D) in an outcome (Y) between two groups ( $h$ and $l$ ):

$$
\mathrm{D}=\mathrm{Yh}-\mathrm{Yl}
$$

into three components. The first component is an intercept effect, indicating the unexplained differences between both groups:

$$
\underbrace{\left(A_{h}-A_{h}\right)}_{\text {Intercept effect }}
$$

The second component quantifies the contribution of differences in composition between both groups. In our case, differences between both groups in the distribution across family structure types X:

$$
\underbrace{\left(\bar{X}_{h}-\bar{X}_{l}\right)\left[\left(\beta_{h}+\beta_{l}\right) / 2\right]}_{\text {Composition effect }}
$$


The third component quantifies the contribution of differences in coefficients $\beta$ related to the covariates $X$ considered:

$$
\underbrace{\left(\beta_{h^{-}} \beta_{l}\right)\left[\left(\bar{X}_{l}+\bar{X}_{h}\right) / 2\right]}_{\text {Coefficient effect }}
$$

One problem with the Blinder-Oaxaca decomposition method is that results can change depending on the reference category chosen for the decomposition variables $X$ (Kim, 2010:626; Yun, 2004). Similar to a constant in a simple OLS regression, the intercept effect changes when the reference categories of covariates change. The difference in intercepts term (equation 2) indicates group differences for the situation where $\bar{X}_{h}$ and $\bar{X}_{l}$ are both zero. In our example, if we include a dummy for whether children grew up with two parents (reference category) or in a non-standard family (value is 1) the intercept effect indicates the outcome difference between groups in the hypothetical situation that all children grew up with two parents. However, if we change the reference category to growing up in a nonstandard family, the intercept effect indicates the outcome difference for the situation where everyone would grow up in a non-standard family. Therefore, if there is any heterogeneity in the effects related to family structure types, changing the reference category will change the estimated intercept effect. It will also change the estimated coefficient effect, because the sum of equations 2 and 4 does not change when the reference category is modified (Kim, 2010:626).

One of the solutions proposed to deal with this problem is to normalize covariates $\mathrm{X}$, a solution also implemented in statistical packages written for the procedure in programs such as STATA. For instance, the oaxaca package (Jann, 2008) includes the option 
normalize(spec) to account for this issue. When normalizing categorical variables results become invariant to the choice of reference category.

In our example, if 50\% of the respondents grew up in a non-standard family (and $50 \%$ with two parents), the intercept term (equation 2) would indicate outcome differences between groups if $50 \%$ of both groups would grow up in a non-standard family, and if there would be no differences in effects of growing up in a non-standard family across groups. This is a counterfactual situation of interest in studies on discrimination, for which the BlinderOaxaca decomposition is primarily used (e.g. Kim, 2010; Yun, 2004). For instance, how big would the gender gap in earnings be if both men and women had a level of education at the sample average, and effects of education would be the same across genders too? However, there are situations where this is not the counterfactual of interest. We argue that in our case it is the comparison to a situation where everybody would grow up in a two-parent family that is of interest, and not group differences in the counterfactual situation where the distribution of family structures within groups would be as the sample average. In other words, the counterfactual question of interest is: Would group differences be smaller if everyone would grow up in a two-parent family? Or: What is the cross-sectional contribution of the existence of non-standard families to group differences in outcome Y?

This argument extends to the question of changes over time too, as we will illustrate with an example in the remainder of this appendix.

\section{Illustrative example:}

Table B1 gives an example of a fictive sample in a given period 0 . The sample contains $50 \%$ children with higher educated mothers and 50\% children with lower educated mothers. Within each group, half grew up with both parents in the household and the other half did 
not. In other words, the distribution of family structure within groups is equal. Within each maternal education group, half of the children attained a college education; hence, there are no differences $D$ in the outcome $Y$ (College Education) between groups $h$ (higher educated mother) and $l$ (lower educated mother). The only difference between both groups is the effect of family structure on college completion. If estimated as two separate LPM models through OLS, without controls, the effect for individuals with higher educated mothers of growing up in a non-standard family is 0.6. For individuals with lower educated mothers the effect is -0.6 . Given that both effects are equal in size, and given that the distribution of family structures is equal, both effects cancel each other out.

Table B1. Frequency of cases with given characteristics in period 0

\begin{tabular}{|l|l|l|l|}
\hline Mother's Education & Family Structure & Outcome Y (dummy) & Frequency \\
\hline High & Non-Standard & College Educated & 8 \\
\hline High & Non-Standard & Not College Educated & 2 \\
\hline High & Two-Parent & College Educated & 2 \\
\hline High & Two-Parent & Not College Educated & 8 \\
\hline Low & Non-Standard & College Educated & 2 \\
\hline Low & Non-Standard & Not College Educated & 8 \\
\hline Low & Two-Parent & College Educated & 8 \\
\hline Low & Two-Parent & Not College Educated & 2 \\
\hline
\end{tabular}

If one would decompose the difference in outcomes between both groups (which is zero in this example) using a normalized version of the variable family structure, the contribution of each component would be 0 . In other words, none of the components of equations 2 to 4 would contribute to group differences in college education. That the contribution of the 
coefficient effect is 0 despite heterogeneity in the effects of family structure makes sense if one is interested in the following counterfactual question: Would group differences be different if there were no heterogeneity in effects? Indeed, in this particular example group differences would not change if the effect of family structure would be equal for both groups (i.e. -0.6 for both groups or 0.6 for both groups).

In contrast, if one would be interested in the counterfactual question "How big would group differences be if everyone would grow up with two parents?" the normalized version of the Blinder-Oaxaca decomposition does not give the right answer. When not normalizing the variable family structure, the intercept effect and the coefficient effect would together still sum up to 0 , but the distribution across both components would be different. When taking growing up in a two-parent family as the reference category (and non-standard family takes on the value 1) the result of the decomposition would be as follows:

Intercept effect: 0.6

Composition effect: 0

Coefficient effect: -0.6

The intercept effect indicates the estimated group differences if everyone were to grow up in a two-parent family. Because the effect of growing up in a non-standard family is positive for individuals with higher educated mothers, college completion rates would be lower for individuals with higher educated mothers in this counterfactual situation. In contrast, the effect of growing up in a non-standard family is negative for individuals with lower educated mothers, and their college completion rates would therefore be higher if everyone grew up with two parents. The intercept effect therefore estimates that group differences $D$ would be 0.6 points lower if everyone were to grow up in a two-parent family. That in the 
current situation there are no group differences in college completion, is due to the different effects related to family structure for both groups. Hence, the positive coefficient effect of 6 .

In short, the intercept effect in a cross-sectional setting estimates group differences in the counterfactual situation that everyone were to grow up with two parents. The coefficient and composition effects together could in that case be regarded as the cross-sectional contribution of the presence of non-standard families to group differences in college completion.

\section{Change over Time}

To illustrate further why this way of estimating the decomposition makes sense for our case, we apply this logic to an example of change over time. Table B1 is taken as the situation in period 0 whereas Table B2 presents the situation for the fictive period 1 . There is only one change as compared to period 0 : the effect of family structure on college completion became weaker for children with lower educated mothers. Whereas the effect of family structure was -0.6 in period 0 the effect was -0.5 in period 1 . The distribution of family structures and effects of family structure for all other groups remained the same. Given that the effect of having lived in a non-standard family is 0.6 for children with higher educated mothers in both periods, the heterogeneity in effects between groups declined across both periods. This process is exactly the part labeled as "Effect of changing heterogeneity in penalties by parental SES" in equation three (3.v). Hence, applying the decomposition of equation 3 to this fictive data should lead to a result where changes in the outcome gap are due to the "Effect of changing heterogeneity in penalties by parental SES". As illustrated in table B3, this is the case when not normalizing family structure, but ceases to be the case when 
normalizing family structure. This renders the former approach more appropriate for our analysis.

Table B2. Frequency of cases with given characteristics in period 1

\begin{tabular}{|l|l|l|l|}
\hline Mother's Education & Family Structure & Outcome Y (dummy) & Frequency \\
\hline High & Non-Standard & College Educated & 8 \\
\hline High & Non-Standard & Not College Educated & 2 \\
\hline High & Two-Parent & College Educated & 2 \\
\hline High & Two-Parent & Not College Educated & 8 \\
\hline Low & Non-Standard & College Educated & $\mathbf{3}$ \\
\hline Low & Non-Standard & Not College Educated & $\mathbf{7}$ \\
\hline Low & Two-Parent & College Educated & 8 \\
\hline Low & Two-Parent & Not College Educated & 2 \\
\hline
\end{tabular}

Table B3. Decomposition of change in group difference in college completion between period 0 and period 1

\begin{tabular}{|c|c|c|c|c|c|c|c|}
\hline & $\begin{array}{l}\text { Gap D } \\
\text { Period } 0\end{array}$ & $\begin{array}{l}\Delta \mathrm{D} \\
\text { Period } 0-1\end{array}$ & $3 . \mathrm{i}$ & 3.ii & 3.iii & 3.iv & $3 . v$ \\
\hline No normalization: & 0 & 0.05 & 0 & 0 & 0 & 0 & 0.05 \\
\hline Normalization: & 0 & 0.05 & 0.05 & 0 & 0 & 0 & 0 \\
\hline
\end{tabular}

Why does normalization provide different results? As proposed by Yun (2004) normalized coefficients can be obtained by taking the average of all possible coefficients with different reference groups (See also Kim, 2010:626). In a case where half of children lived in nonstandard families and another half lived in two-parent families, any increase in the coefficient of growing up in a non-standard family is paralleled by an equally large change 
in the coefficient of growing up in a two-parent family (i.e. switching the reference category). Summing up these different contributions leads to a zero change in heterogeneity in effects.

To illustrate, run the following commands in STATA on the data of Tables B1 and B2 using the oaxaca command (install package st0152_1)

oaxaca college normalize(famstr famstr_0) if period $==0$, by(groups) $d$ pooled noisily

oaxaca college normalize(famstr famstr_0) if period $==1$, by(groups) $d$ pooled noisily

Where "college" is the dummy variable indicating college completion, "famstr" indicates a dummy variable having grown up in a non-standard family and "famstr_0" is the same variable but changing the reference category. "Groups" distinguishes between children with higher educated (1) and lower educated (0) parents.

Yun, Myeong-Su. 2004. "Decomposing differences in the first moment." Economics Letters 82: $275-280$. 
Online Appendix C. OLS and Sibling Fixed-Effects Models Explaining Bachelor Degree Attainment

\begin{tabular}{|c|c|c|c|c|c|c|c|c|}
\hline & \multicolumn{4}{|c|}{ NLSY79 } & \multicolumn{4}{|c|}{ NLSY97 } \\
\hline & \multicolumn{2}{|c|}{ OLS } & \multicolumn{2}{|c|}{ Sibling-fx } & \multicolumn{2}{|c|}{ OLS } & \multicolumn{2}{|c|}{ Sibling-fx } \\
\hline \multicolumn{9}{|l|}{$\begin{array}{l}\text { Maternal Education } \\
\text { (Ref. Lowest } 17 \% \text { of distribution) }\end{array}$} \\
\hline Middle educated & $0.14 * * *$ & 0.02 & -0.02 & 0.04 & $0.19 * * *$ & 0.03 & 0.11 & 0.15 \\
\hline Highest educated (top 21\%) & $0.49 * * *$ & 0.03 & -0.08 & 0.08 & $0.55 * * *$ & 0.04 & $0.50 *$ & 0.25 \\
\hline \multicolumn{9}{|l|}{ Family Structure } \\
\hline \multicolumn{9}{|l|}{ Socioeconomic differences in penalty } \\
\hline Non-standard X Mid educated mother & $-0.06 *$ & 0.03 & -0.02 & 0.05 & $-0.09 * *$ & 0.03 & -0.04 & 0.14 \\
\hline Non-standard X Higher educated mother & $-0.11 *$ & 0.05 & $0.22 \dagger$ & 0.12 & $-0.27 * * *$ & 0.05 & $-0.55^{*}$ & 0.22 \\
\hline Female & 0.01 & 0.02 & 0.00 & 0.02 & $0.14 * * *$ & 0.04 & 0.08 & 0.06 \\
\hline \multicolumn{9}{|l|}{ Three-way interaction } \\
\hline Non-standard X Female X Mid-educated mother & 0.00 & 0.04 & 0.00 & 0.04 & 0.04 & 0.05 & 0.00 & 0.09 \\
\hline Non-standard X Female X Higher-educated mother & $-0.12+$ & 0.08 & $-0.25^{*}$ & 0.11 & $0.21 * *$ & 0.08 & $0.32 *$ & 0.15 \\
\hline Constant & 0.018 & 0.02 & 0.240 & 0.03 & $0.126 * * *$ & 003 & 0.148 & 0.12 \\
\hline $\mathrm{N}$ & 7,422 & & 7,422 & & 6,379 & & 6,379 & \\
\hline Number of households & & & 5,221 & & & & 5,099 & \\
\hline
\end{tabular}

Sibling-fx = Sibling fixed-effects models. Controls included are maternal education, age, ethnicity, region for OLS models, only age for fixed effects models. Sample weights included. Standard errors clustered by original household in OLS models.

Note. The main effects for maternal education and family structure are estimated in the fixed-effects models because they differ for some of the sibling-dyads. Their interpretation, however, is not straightforward. The interaction effects with gender, however, give an indication of how gender differences in education among siblings differ for the different subgroups considered. 
Online Appendix D. Robustness checks

Replication of decomposition analysis presented in Table 4 for various alternative specifications:

$\begin{array}{llllllllll}\text { Boys } & \text { Gap R } & \Delta \mathrm{R} & 3 . \mathrm{i} & 3 . \mathrm{ii} & 3 . \mathrm{iii} & 3 . \mathrm{iv} & 3 . \mathrm{v} & \begin{array}{l}\text { Total } \\ \text { 3.ii-3.v }\end{array} & \begin{array}{l}\text { As \% of } \\ \mathrm{R} \text { in } \\ \text { 1 }\end{array} \\ & 1979 & & & & & & & & \end{array}$

Main Specification :

$\begin{array}{lllllllll}0.476 & 0.025 & 0.088 & -0.030 & 0.021 & 0.022 & -0.075 & --0.063 & -13.2\end{array}$

Bachelor Degree

Alternative Specifications:

\begin{tabular}{llllllllll}
\hline Absolute Education Mother & 0.547 & -0.046 & 0.022 & -0.034 & 0.019 & 0.020 & -0.074 & -0.069 & -12.6 \\
Multiple Imputation & 0.464 & 0.055 & 0.089 & -0.024 & 0.019 & 0.015 & -0.044 & -0.034 & -7.3 \\
MI + Father's Education & 0.413 & 0.087 & 0.107 & -0.019 & 0.026 & 0.014 & -0.042 & 0.020 & -4.8
\end{tabular}

Replication using GSS:

Bachelor Degree

\begin{tabular}{|c|c|c|c|c|c|c|c|c|c|}
\hline & 0.355 & 0.063 & 0.167 & -0.006 & -0.000 & 0.004 & -0.093 & -0.074 & -20.8 \\
\hline Girls & $\begin{array}{l}\text { Gap R } \\
1979\end{array}$ & $\overline{\Delta \Delta \mathrm{R}}$ & $3 . \mathrm{i}$ & 3.ii & 3.iii & 3.iv & $3 . \mathrm{v}$ & $\begin{array}{l}\text { Total } \\
\text { 3.ii-3.v }\end{array}$ & $\begin{array}{l}\text { As \% of } \\
R \text { in }\end{array}$ \\
\hline
\end{tabular}

Specification:

$\begin{array}{lllllllll}0.461 & 0.125 & 0.056 & -0.025 & 0.025 & 0.009 & 0.061 & 0.070 & 15.2\end{array}$

Alternative Specifications:

\begin{tabular}{llllllllll}
\hline Absolute Education Mother & 0.585 & 0.002 & -0.074 & -0.036 & 0.024 & -0.000 & 0.088 & 0.076 & 13.0 \\
Multiple Imputation & 0.458 & 0.142 & 0.063 & -0.021 & 0.024 & 0.004 & 0.071 & 0.078 & 17.0 \\
MI + Father's Education & 0.444 & 0.107 & 0.062 & -0.023 & 0.024 & 0.013 & 0.036 & 0.045 & 10.1
\end{tabular}

\section{Replication using GSS: \\ Bachelor Degree}

$\begin{array}{lllllllll}0.371 & 0.098 & 0.104 & -0.016 & 0.013 & 0.015 & -0.018 & -0.006 & -1.6\end{array}$

Controls included are maternal education, age, region and ethnicity. Sample weights included. D = Difference in outcome between individuals with higher - lower educated mothers in 1979; $\Delta \mathrm{D}$ Absolute change in difference D between 1997 and 1979; 3.i = Intercept Effect; 3.ii = Due to average change in prevalence of family structures; 3. iii = Due to change in socioeconomic prevalence differences; 3. iv = Due to change over time in average penalties; 3.v = Due to change in socioeconomic difference in penalties.

Bachelor are identical to the main result of Table 4.

Absolute Education Mother are models considering absolute levels of maternal education;

higher educated mother are defined as having four years of college or more, and lower educated mother as less than 12 years of education for both cohorts. 
Multiple Imputation is based on 20 imputations imputing missing information on independent variables. The imputation models include all cases with an interview in 1994 (NLSY79) or 2015 (NLSY97). Cases with missing information on the outcome variable are excluded after the imputation. The prediction model consisted of all independent variables, years of education plus father's education. The imputation model was estimated using chained equations. Imputed values for mother's education, father's education are based on ordered logit models; for region and family structure on multinomial logit models, and years of education on a predictive mean matching method. The results for Multiple Imputation use this data to estimate the equivalent of the results underlying Figure 4.

$M I+$ Father's Education is based on the imputed data but using father's education instead of mother's education. Because father's education is more often missing, and especially for individuals who lived primarily with their mother during childhood, we considered the imputed data more appropriate for this specification.

Replication using GSS: These models are based on all GSS waves available up to date (version: GSS7218_R1.DTA). Individuals are selected if they were born between 1957 and 1965 (NLSY79 cohort equivalent) and between ages 29-37 at the time of interview (agerange of NLSY79 cohort in 1994) or if they were born between 1979 and 1985 (NLSY97 cohort equivalent) and between ages 29-37 at the time of interview. The variable educ is used as years of education, the variable family 16 is used for information on family structure at age 16 (categories: mother \& father; parent \& step-parent; one parent only; other). Maeduc is the variable used for maternal education and the same relative levels of education across cohorts are constructed as in the original analysis. Sample weights are included (wtssnr). Region. Race and Age are included as controls and sex as the variable to split the sample. 
Figure D1. Bachelor degree attainment by cohort, childhood family structure and maternal education based on the General Social Survey

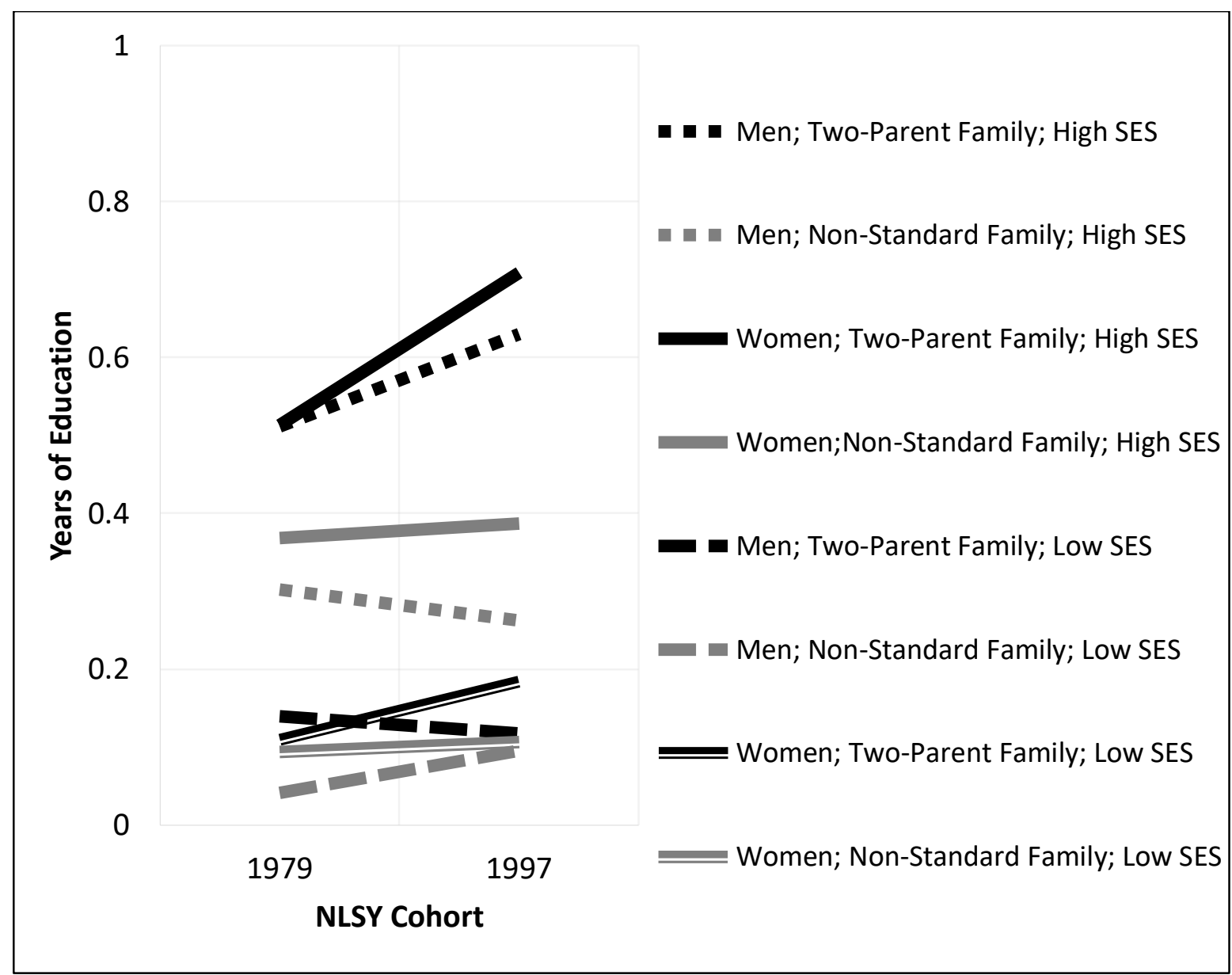

Note. Sample weights included. Controlled for age at interview. 
Online Appendix E. Decomposition of the cross-sectional contribution of family structure to the socioeconomic gap in years of education in 1997

\begin{tabular}{|c|c|c|c|c|}
\hline & \multicolumn{2}{|l|}{ Men } & \multicolumn{2}{|l|}{ Women } \\
\hline & Coef. & SE & Coef. & SE \\
\hline Actual difference (high-low educated mothers) & $0.501 * * *$ & 0.02 & $0.586 * * *$ & 0.02 \\
\hline Difference due to prevalence: controls & 0.012 & 0.07 & $0.017+$ & 0.01 \\
\hline Difference due to penalties: controls & 0.062 & 0.06 & 0.012 & 0.05 \\
\hline Difference net of controls & 0.427 & & 0.557 & \\
\hline $\begin{array}{l}\text { Difference due to socioeconomic differences in } \\
\text { prevalence of family structure: Total }\end{array}$ & $0.054 * * *$ & 0.01 & $0.061 * * *$ & 0.01 \\
\hline Step-parent families & $0.012 *$ & 0.03 & $0.011 *$ & 0.01 \\
\hline Single-parent families & $0.030 * * *$ & 0.04 & $0.021 * * *$ & 0.01 \\
\hline Other family forms & $0.013 * * *$ & 0.04 & $0.029 * * *$ & 0.01 \\
\hline $\begin{array}{l}\text { Difference due to socioeconomic differences in } \\
\text { penalties of family structure: Total }\end{array}$ & $-0.130 * * *$ & 0.16 & -0.032 & 0.03 \\
\hline Step-parent families & $-0.03 * *$ & 0.01 & -0.02 & 0.01 \\
\hline Single-parent families & $-0.09 * * *$ & 0.02 & -0.01 & 0.02 \\
\hline Other family forms & $-0.01 \dagger$ & 0.01 & -0.01 & 0.01 \\
\hline Total accounted for by family structure & -0.076 & & 0.029 & \\
\hline As \% of actual background difference & -15.1 & & 4.9 & \\
\hline As \% of background difference net of controls & -17.8 & & 5.2 & \\
\hline $\mathrm{N}$ & 1,281 & & 1,316 & \\
\hline
\end{tabular}

Controls included are maternal education, age, region, and ethnicity. Sample weights included. 